\title{
Review of oral appliances for treatment of sleep-disordered breathing
}

\author{
Victor Hoffstein
}

Published online: 29 November 2006

(C) Springer-Verlag 2006

\begin{abstract}
Between 1982 and 2006, there were 89 distinct publications dealing with oral appliance therapy involving a total of 3,027 patients, which reported results of sleep studies performed with and without the appliance. These studies, which constitute a very heterogeneous group in terms of methodology and patient population, are reviewed and the results summarized. This review focused on the following outcomes: sleep apnea (i.e. reduction in the apnea/hypopnea index or respiratory disturbance index), ability of oral appliances to reduce snoring, effect of oral appliances on daytime function, comparison of oral appliances with other treatments (continuous positive airway pressure and surgery), side effects, dental changes (overbite and overjet), and long-term compliance. We found that the success rate, defined as the ability of the oral appliances to reduce apnea/hypopnea index to less than 10 , is $54 \%$. The response rate, defined as at least $50 \%$ reduction in the initial apnea/ hypopnea index (although it still remained above 10), is $21 \%$. When only the results of randomized, crossover, placebo-controlled studies are considered, the success and response rates are $50 \%$ and $14 \%$, respectively. Snoring was reduced by $45 \%$. In the studies comparing oral appliances to continuous positive airway pressure (CPAP) or to uvulopalatopharyngoplasty (UPPP), an appliance reduced initial AHI by $42 \%$, CPAP reduced it by $75 \%$, and UPPP by $30 \%$. The majority of patients prefer using oral appliance than CPAP. Use of oral appliances improves daytime function somewhat; the Epworth sleepiness score (ESS) dropped from 11.2 to 7.8 in 854 patients. A summary of the follow-up
\end{abstract}

\section{Hoffstein $(\triangle)$}

Department of Medicine, University of Toronto,

St. Michael's Hospital,

30 Bond Street,

Toronto, ON, Canada M5B 1W8

e-mail: victor.hoffstein@utoronto.ca compliance data shows that at 30 months, $56-68 \%$ of patients continue to use oral appliance. Side effects are relatively minor but frequent. The most common ones are excessive salivation and teeth discomfort. Efficacy and side effects depend on the type of appliance, degree of protrusion, vertical opening, and other settings. We conclude that oral appliances, although not as effective as CPAP in reducing sleep apnea, snoring, and improving daytime function, have a definite role in the treatment of snoring and sleep apnea.

Keywords Continuous positive airway pressure . Sleep apnea $\cdot$ Oral appliance

\section{Introduction}

Treatment of sleep-disordered breathing (i.e. snoring, upper airway resistance syndrome, sleep apnea syndrome) can be divided into four general categories. These include: (1) lifestyle modification, i.e. weight loss, cessation of evening alcohol ingestion, sleep position training, (2) upper airway surgery, (3) oral appliances, and (4) CPAP. Although the latter category provides the most reliable therapeutic modality and is the most widely used method to treat sleepdisordered breathing today-it is also the most cumbersome one. Many patients, particularly young non-apneic snorers, find it unappealing, difficult to tolerate, and unacceptable. The only other non-invasive alternative, which can produce favorable results within a short time, is oral appliances.

Although there are several reviews of oral appliances, which have appeared since the start of the new millennium [1-6], including a recent review and practice parameters for treatment of snoring and sleep apnea [124, 125], this treatment modality is still underutilized. Even the dentists who are primary providers of this treatment, lack education 
in this area. For example, Bian [7] surveyed 500 general dentists in the state of Indiana and found that $40 \%$ "knew little or nothing about oral appliances for treatment of obstructive sleep apnea". Unarguably, the knowledge about oral appliances among dentists and physicians varies geographically, being higher in large urban centers, which provide more educational opportunities locally, but the results of the survey certainly indicate a need for more education in this area.

This review will summarize our current state of knowledge of the efficacy of oral appliances for the treatment of snoring and obstructive sleep apnea. We shall not limit this review to a simple summary of the effect of oral appliances on nocturnal respiration, but will also examine other aspects of this therapy, such as the reduction in symptoms, vascular consequences, side effects, and compliance. However, the main objective of this review will remain to be the examination of the current data dealing with the efficacy of oral appliance therapy for the treatment of snoring and sleep apnea.

\section{Historical aspects}

George Cattlin [8] was probably the first person who seriously thought that the route of breathing may influence sleep quality and daytime function. He attributed good health of the native North American Indians, compared to their immigrant European counterparts, to the fact that they are taught, from the early age, to breathe through the nose rather than the mouth. He pointed out that breathing through the nose promotes more restful and better quality sleep, which translates into better daytime function and better general health. After the publication of his book, there appeared many patents describing devices designed to promote nasal breathing. Some of the early patented appliances are shown in Fig. 1.

However, modern published clinical work begins in 1903, when Pierre Robin first described a device, called the "monoblock", for the treatment of glossoptosis [9]. More than 30 years later, he used an oral appliance to reposition the mandible [10]. For the next 50 years, little work was done in this field. It took almost another 50 years to start using oral appliances for the treatment of snoring and sleep apnea when Cartwright and Samelson [11] described the tongue retaining device in 1982. This work stimulated further investigations, resulting in many subsequent studies, many of which will be summarized in this review.

\section{Types of appliances}

Although the type and number of specific appliances may be bewildering and is still growing (Table 1), all may be divided into three general groups: soft palate lifters (SPL), tongue retaining devices (TRD), and mandibular advancement appliances (MAA). The first category is virtually no longer in use today. The second category is used very seldom, mainly if there are dental reasons precluding the construction of MAA. The last category (MAA) is by far the most common type of dental appliance in use today. It protrudes the mandible forward, thus preventing or minimizing upper airway collapse during sleep. These devices can be either fixed (i.e. the protrusion distance cannot be changed), or variable (i.e. protrusion can be increased or decreased). The final protrusion distance represents a delicate balance between side effects and efficacy. For this reason, the construction and fitting of the appliance should be done by a dentist with an expertise in this area who is familiar with different appliances, is capable of selecting the appropriate one based on the dental examination and has access to a sleep laboratory where the objective efficacy of the appliance can be verified.

\section{Mechanism of action of oral appliances}

Much was written on how and why oral appliances may improve snoring and sleep apnea. The results show that upper airway obstruction during sleep may occur at any site between the nasopharynx and the larynx. The most common sites of obstruction are behind the base of the tongue (retroglossal) and behind the soft palate (retropalatal). This partial or complete occlusion of the upper airway during sleep is a consequence of abnormal anatomy and physiology (i.e. the airway is narrow and "floppy"). There is still a lively debate as to the relative contributions of abnormal anatomy vs abnormal physiology in the pathogenesis of upper airway obstruction during sleep [12, 13]. This debate is partially fuelled by the fact that airway narrowing or even a complete occlusion is a normal physiological event during sleep. In patients with sleep apnea, this normal response is exaggerated. The question then becomes whether this exaggerated response is due to abnormal neuromuscular control superimposed on the otherwise anatomically normal airway, or is the airway anatomically narrower than normal without any abnormalities in the neuromuscular control. It is now an accepted fact that a combination of abnormal anatomy and physiology is necessary to produce pathological repetitive narrowing (or complete occlusion) of upper airway during sleep-i.e. sleep apnea.

Given that sleep apnea and snoring are a consequence of abnormal anatomy and physiology of the upper airway, is there evidence that oral appliances can correct these abnormalities, at least in some patients? There are several studies, not only during wakefulness, but also during sleep, 
Fig. 1 Examples of early oral appliances

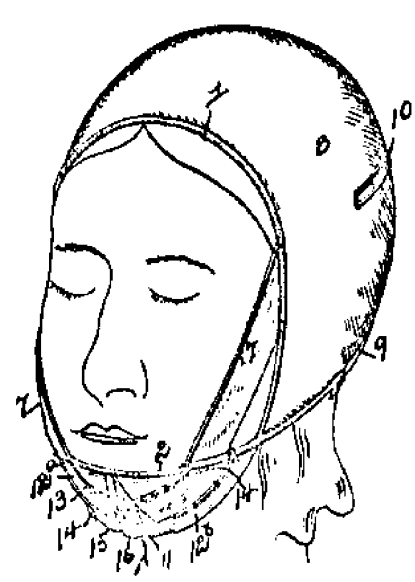

1896

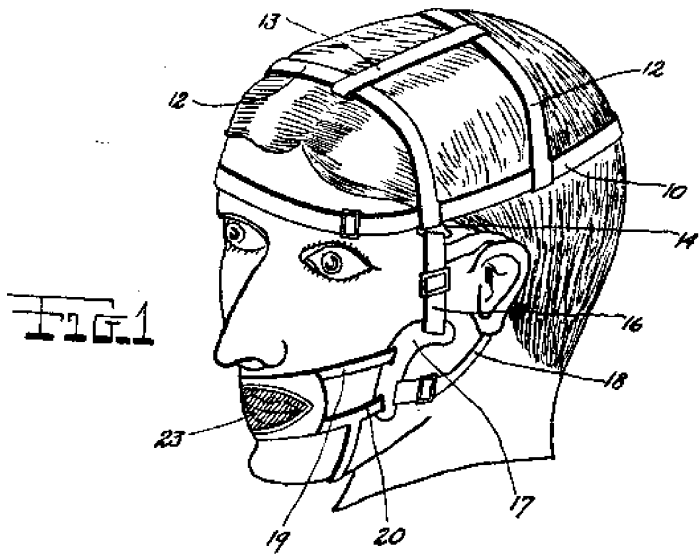

1924
PILED 1899

Fig.l.

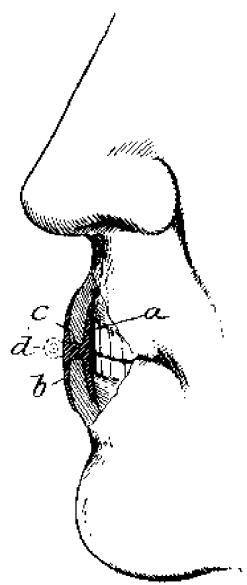

1899

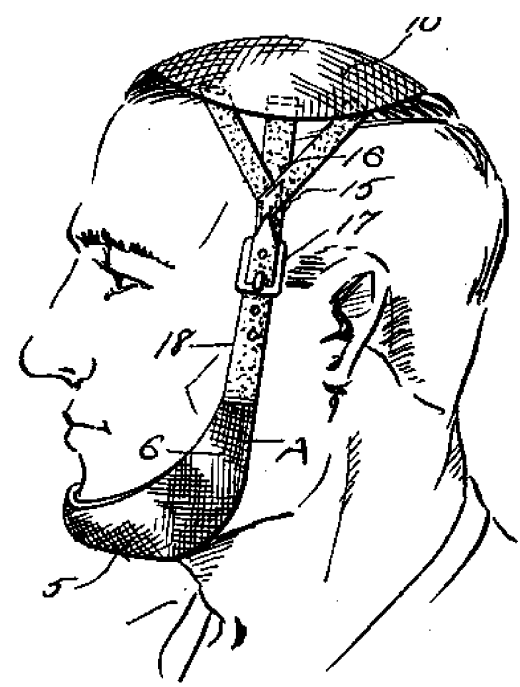

1928 indicating that advancing the mandible forward can enlarge the airway and reduce pharyngeal collapsibility [14-19, 120,123 ] in normal subjects and patients with sleep apnea. These investigations confirmed the effect of oral appliances on upper airway properties. Some authors suggested that

Table 1 Examples of oral appliances

\section{Oral appliances}

\begin{tabular}{lll}
\hline The Equilizer & Jasper jumper & Esmark \\
The Silencer & PM Positioner & TPE \\
Klearway & Tongue locking appliance & SnoreEx \\
NAPA & Adjustable soft palate lifter & HAP \\
TAP & Z-training appliance & Tessi \\
TOPS & Snore-no-more & Snore Guard \\
SNOAR & Elastometric & Silent Night \\
Herbst & SUAD & TheraSnore \\
\hline
\end{tabular}

measurements of airway pressures during sleep may even predict the beneficial response to oral appliances. For example, recently, Battagel et al. [19] performed sleep nasendoscopy in 27 patients with sleep apnea. The mandible was gently advanced by $4-5 \mathrm{~mm}$ to simulate the effect of the mandibular appliance. The authors suggested that this procedure may help to determine whether a particular patient is a candidate for oral appliance therapy. Similarly, $\mathrm{Ng}$ et al. [123] measured upper airway pressures during natural sleep in 12 patients with obstructive sleep apnea to identify the site of airway collapse. The authors found that oropharyngeal, rather than velopharyngeal collapse, was predictive of the beneficial response to oral appliance. However, another study of 25 patients with sleep apnea where esophageal pressure was measured during sleep, found no significant differences in nadir esophageal pressure or cephalometric parameters between 
the patients who responded to oral appliance therapy and those who did not [120].

It is safe to conclude at this time that anatomical changes in the oropharynx, produced by mandibular advancement, result in the alterations of the intricate relationships between different muscle groups controlling the upper airway caliber. In some patients with sleep apnea these alterations may prevent the obstruction, in others-worsen the obstruction, and yet in others, particularly in those with low level obstruction, the part of the airway where the obstruction occurs may be unaffected. There is currently no reliable way to predict the outcome of treatment with oral appliance in individual patients and therefore to select appropriate candidates for this treatment. Clinical features also do not seem to offer much help in trying to predict who will respond to oral appliances, or just the opposite, to identify patients who are not likely to respond to this therapy. When two expert maxillofacial surgeons examined (in a blind fashion) 100 patients with sleep apnea to determine if there were any contraindications to mandibular advancement devices, they found that primary contraindications were present in $34 \%$ of patients [20]. This relatively high rate of contraindications and disagreements between individual experts only point out that a team approach is necessary to select the proper treatment for patients with sleep apnea.

\section{Results of clinical trials}

The onset of the new millennium carried forward the momentum started by Cartwright and Samelson [11] resulting in the increased use of oral appliances for the treatment of snoring and sleep apnea. However, the emphasis on the type of appliances has changed. Tongue retaining devices are currently seldom used, being almost completely replaced by the mandibular advancement appliances. The latter are sometimes also called mandibular repositioners, protruders, devices, splints, prosthesis, etc.but the common feature of all these appliances is their ability to adjust the degree of mandibular advancement to achieve resolution of snoring and sleep apnea.

In what follows, we shall summarize the results of clinical trials employing oral appliances for the treatment of sleep apnea and snoring. In addition, we shall review and summarize the information regarding changes in daytime function as a result of using the appliance, clinical and dental side effects, and compliance with treatment.

Oral appliances for the treatment of sleep apnea

Table 2 summarizes the results of individual studies using oral appliances starting with the 1982 polysomnographic study of TRD by Cartwright and Samelson [11] until the present. The only criterion for the inclusion of a particular study into this table, and thus the only common feature of all studies listed, was the availability of at least partial results of nocturnal monitoring of respiration with and without oral appliance. Otherwise, the studies are highly variable in their design, methodology, data analysis, outcome definition and assessment and presentation of results. This makes the interpretation of individual results, and particularly any attempt to summarize all of them, very challenging. Before describing the methods of analysis and presenting the summary of the data, it is very important to keep in mind the following points.

First, Table 2 contains the studies from the two extreme ends of the spectrum of scientific rigor. At the highest end of the spectrum there are prospective, randomized, crossover, controlled (either against placebo-appliance or another treatment modality) studies. At the lowest end of the spectrum are individual case reports. Some studies are prospective case series, but most studies are retrospective analysis of series of cases.

Second, the investigations listed in Table 2 form a very inhomogeneous group with respect to several variables: time of follow-up study, type of polysomnography, which respiratory variables measured, presentation of results, type of oral appliance used, missing data, etc. The time interval between the diagnostic and "with appliance" polysomnography varied from a few hours to a few months. In some studies, split polysomnography (i.e. diagnostic part followed by "with appliance" part) was carried out, while in others, the two sleep studies were separated by a couple of days to several months. In some investigations, formal inhospital polysomnography was performed, while in others, only at-home monitoring of oxygen saturation was carried out. In some of the earliest investigations, only the apnea index (AI) was measured. Later investigations reported the oxygen desaturation index (number of times per hour of sleep that oxygen saturation falls by more the $4 \%$ from the baseline-ODI4). Recent investigations all reported either the apnea-hypopnea index (AHI) or the respiratory disturbance index (RDI). Most investigations presented only the mean values, rather than the individual data, and some presented only the median values. Oral appliances used by the investigators included tongue retaining devices, soft palate lifters, and fixed and variable mandibular advancement appliances. In the vast majority of investigations, the mandibular advancement appliance was used, less than ten investigations employed the TRD, and only one investigation used the soft palate lifter. In many investigations, not all patients who had a diagnostic sleep study also had a follow-up "with appliance" study.

Clearly, the above factors have a significant effect on the analysis of the pooled data presented in Table 2 . 
Table 2 Clinical studies with oral appliances: 1982-2005

\begin{tabular}{|c|c|c|c|c|c|c|c|}
\hline Reference & $N$ & Type & $\mathrm{AHI}_{\text {base }}$ & $\mathrm{AHI}_{\mathrm{appl}}$ & $\begin{array}{l}\text { Success } \\
\text { rate }(\%)\end{array}$ & $\begin{array}{l}\text { Response } \\
\text { rate }(\%)\end{array}$ & Comments \\
\hline$[11]$ & 14 & TRD & 56 & 27 & 14 & 14 & Case series; $\mathrm{AI}$ \\
\hline$[22]$ & 16 & TRD & 54 & 33 & 19 & 32 & Case series; AI \\
\hline$[23]$ & 16 & TRD & - & - & - & 56 & Case series; all patients had SMR or UPPP; AI \\
\hline$[24]$ & 1 & TRD & 79 & 5 & 100 & - & Case report; $\mathrm{AI}$ \\
\hline$[25]$ & 7 & MAA & 37 & 12 & 57 & 43 & Case series; Esmarch prosthesis; AI \\
\hline$[26]$ & 44 & MAA & 50 & 23 & - & 59 & Case series; Esmarch prosthesis; AI \\
\hline$[27]$ & 5 & TRD & 48 & 9 & 40 & 60 & Case series; NAPA; AI \\
\hline$[28]$ & 12 & MAA & 54 & 36 & 25 & 17 & Case series; modified functional appliance \\
\hline [29] & 1 & MAA & 35 & 9 & 100 & - & Case report; mandibular repositioning appliance \\
\hline$[30]$ & 12 & TRD & 37 & 17 & 58 & 17 & Case series \\
\hline$[31]$ & 1 & MAA & 57 & 2 & 100 & - & Case report; mandibular repositioning appliance \\
\hline$[32]$ & 15 & TRD & 27 & 11 & 73 & 0 & Case series \\
\hline$[33]$ & 14 & MAA & 32 & 9 & 43 & 57 & Case series; fixed splint; AI \\
\hline [34] & 20 & MAA & 47 & 20 & 35 & 40 & Case series; fixed dental orthosis \\
\hline$[35]$ & 12 & MAA & 50 & 19 & - & - & Case series; fixed prosthesis; AI \\
\hline$[36]$ & 2 & MAA & 30 & 7 & 50 & 50 & Two case reports; intra-oral fixed prosthesis; RDI \\
\hline$[37]$ & 16 & MAA & 37 & 9 & 69 & 25 & Case series; NAPA; RDI \\
\hline [38] & 24 & MAA & 48 & 12 & 73 & 13 & Prospective case series; Herbst-like; RDI \\
\hline [39] & 19 & MAA & 35 & 13 & - & - & Case series of CPAP failures; Herbst \\
\hline$[40]$ & 20 & MAA & 57 & 26 & 20 & 40 & Case series; Esmarch; AI \\
\hline$[41]$ & 12 & MAA & 45 & 30 & - & - & $\begin{array}{l}\text { Case series; Herbst vs MR (muscle relaxation) appliance; result } \\
\text { for Herbst; ODI4 }\end{array}$ \\
\hline [41] & 12 & MAA & 45 & 41 & - & - & $\begin{array}{l}\text { Case series; Herbst vs MR (muscle relaxation) appliance; result } \\
\text { for MR; ODI4 }\end{array}$ \\
\hline [42] & 51 & MAA & 32 & 18 & - & - & $\begin{array}{l}\text { Case series; mandibular advancement splint fixed } 75 \% \text { of } \\
\text { maximum protrusion }\end{array}$ \\
\hline$[43]$ & 4 & MAA & 200 & 110 & - & 75 & Case series; fixed intra-oral prosthesis; apneas/night \\
\hline$[44]$ & 30 & MAA & 65 & 31 & - & - & Case series; Esmarch; AI \\
\hline$[45]$ & 21 & MAA & 34 & 20 & 19 & 24 & Crossover, comparing AMP device with CPAP \\
\hline$[46]$ & 19 & MAA & 20 & 10 & 68 & 11 & $\begin{array}{l}\text { Randomized, prospective crossover comparing the Snore-Guard } \\
\text { with CPAP }\end{array}$ \\
\hline$[47]$ & 23 & MAA & 37 & 18 & 52 & 30 & $\begin{array}{l}\text { Case series; mandibular repositioning device;most patients were } \\
\text { CPAP failures; RDI }\end{array}$ \\
\hline$[48]$ & 1 & MAA & 34 & 3 & 100 & - & Case report; elastometric sleep appliance \\
\hline [49] & 14 & TRD & 38 & 30 & 0 & 0 & Case series: SnorEx appliance; RDI \\
\hline$[50]$ & 20 & MAA & 25 & 14 & 55 & 21 & Randomized, crossover comparing the AMP device with CPAP \\
\hline$[51]$ & 8 & MAA & 44 & 12 & 63 & 13 & Case series; mandibular advancing positioner \\
\hline$[52]$ & 1 & MAA & 53 & 4 & 100 & - & Case report; fixed dental appliance \\
\hline$[53]$ & 14 & MAA & 4 & 4 & - & - & Fixed mandibular splint; maximum protrusion; median AHI \\
\hline$[53]$ & 9 & MAA & 7 & 1 & - & - & $\begin{array}{l}\text { Fixed mandibular splint; } 70 \% \text { of maximum protrusion; median } \\
\text { AHI }\end{array}$ \\
\hline$[54]$ & 44 & MAA & 25 & 9 & 64 & 16 & Case series, prospective; mandibular advancement device \\
\hline$[55]$ & 18 & MAA & 42 & 15 & 61 & 11 & Case series of UPPP failures; Herbst \\
\hline$[56]$ & 25 & MAA & 33 & 9 & 72 & 12 & Case series;mandibular positioning device; RDI \\
\hline$[57]$ & 15 & MAA & 193 & 20 & - & - & $\begin{array}{l}\text { Case series of snorers; mandibular advancement device; snores/ } \\
\mathrm{h} \text { of sleep }\end{array}$ \\
\hline$[58]$ & 14 & MAA & 36 & 5 & 71 & 21 & Case series; Serenox \\
\hline [59] & 41 & MAA & 18 & 12 & 78 & 3 & $\begin{array}{l}\text { Prospective, randomized, parallel groups comparing dental } \\
\text { appliance with UPPP }\end{array}$ \\
\hline$[60]$ & 75 & MAA & 44 & 12 & 51 & 28 & Case series; TAP appliance \\
\hline$[61]$ & 11 & MAA & 45 & 10 & - & - & Case series; dental appliance \\
\hline$[62]$ & 15 & MAA & 28 & 8 & - & - & Case series; Klearway appliance \\
\hline$[63]$ & 28 & MAA & 53 & 21 & 32 & 36 & Case series; elastic mandibular advancement device \\
\hline$[64]$ & 37 & MAA & 26 & 11 & 50 & 15 & $\begin{array}{l}\text { Case series; three fixed appliances with 2, } 4 \text { and } 6 \mathrm{~mm} \text { protrusion; } \\
\text { ODI } 4\end{array}$ \\
\hline
\end{tabular}


Table 2 (continued)

\begin{tabular}{|c|c|c|c|c|c|c|c|}
\hline Reference & $N$ & Type & $\mathrm{AHI}_{\text {base }}$ & $\mathrm{AHI}_{\mathrm{appl}}$ & $\begin{array}{l}\text { Success } \\
\text { rate }(\%)\end{array}$ & $\begin{array}{l}\text { Response } \\
\text { rate }(\%)\end{array}$ & Comments \\
\hline$[65]$ & 8 & MAA & 72 & 36 & 13 & 50 & $\begin{array}{l}\text { Case series comparing MAA (Snore-Guard) with TRD and with } \\
\text { soft palate lifter (SPL) }\end{array}$ \\
\hline$[65]$ & 5 & TRD & 50 & 44 & - & - & Ibid \\
\hline$[65]$ & 2 & SPL & 47 & 57 & - & - & Ibid \\
\hline$[66]$ & 10 & MAA & 41 & 12 & 60 & 30 & Case series; Herbst \\
\hline$[67]$ & 38 & MAA & 33 & 12 & 55 & 18 & Case series; Klearway \\
\hline$[68]$ & 24 & MAA & 23 & 9 & 67 & - & $\begin{array}{l}\text { Randomized, crossover comparing Herbst vs monoblock; results } \\
\text { given for Herbst }\end{array}$ \\
\hline [69] & 39 & MAA & 17 & 8 & 59 & - & Case series; SnorBan \\
\hline$[70]$ & 256 & MAA & 43 & 18 & 54 & 14 & Case series; mandibular advancement device \\
\hline [71] & 22 & MAA & 40 & 12 & 59 & 23 & Case series; modified functional appliance \\
\hline$[72]$ & 24 & MAA & 30 & 14 & 38 & 25 & $\begin{array}{l}\text { Randomized, placebo-appliance-controlled, crossover; mandibular } \\
\text { advancement splint }\end{array}$ \\
\hline$[73]$ & 22 & MAA & 28 & 6 & - & - & Case series; either Herbst or monoblock \\
\hline$[74]$ & 72 & MAA & 43 & 22 & 53 & 22 & Case series; adjustable mandibular splints \\
\hline$[75]$ & 25 & MAA & 3.4 & 1.8 & - & - & $\begin{array}{l}\text { Randomized, placebo-appliance-controlled, crossover series of } \\
\text { snorers; snoring measured on a } 0-4 \text { scale }\end{array}$ \\
\hline$[76]$ & 33 & MAA & 25 & 9 & 58 & - & Prospective case series; mandibular advancement device \\
\hline$[77]$ & 23 & MAA & 21 & 8 & 52 & 22 & $\begin{array}{l}\text { Randomized, crossover, comparing } 4 \mathrm{~mm} \text { with } 14 \mathrm{~mm} \\
\text { inter-incisal opening; results for } 4 \mathrm{~mm} \text { opening }\end{array}$ \\
\hline$[78]$ & 7 & MAA & 67 & 20 & 43 & 43 & Case series; Herbst-like \\
\hline [79] & 32 & MAA & 18 & 7 & 63 & 9 & Randomized, parallel groups comparing UPPP and MAA \\
\hline$[80]$ & 26 & MAA & 18 & 8 & 88 & 12 & Case series; Karwetzky activator \\
\hline [81] & 34 & MAA & 22 & 7 & - & - & Case series; Karwetzky activator; median AHIs \\
\hline$[82]$ & 73 & MAA & 27 & 12 & 36 & 27 & Randomized, crossover, placebo-appliance-controlled \\
\hline$[83]$ & 6 & MAA & 13 & 6 & 83 & 0 & $\begin{array}{l}\text { Case series; titration study; results for maximum protrusion; } \\
\text { Klearway }\end{array}$ \\
\hline [84] & 20 & MAA & 18 & 14 & 30 & - & Randomized, crossover, comparing CPAP with ISAD appliance \\
\hline [85] & 48 & MAA & 31 & 15 & 47 & - & $\begin{array}{l}\text { Randomized, crossover, comparing CPAP with mandibular } \\
\text { repositioning splint }\end{array}$ \\
\hline [86] & 20 & MAA & 38 & 23 & 33 & - & $\begin{array}{l}\text { Randomized, crossover, placebo-appliance-controlled; mandibular } \\
\text { advancement splint }\end{array}$ \\
\hline [87] & 34 & MAA & 29 & 4 & - & - & Case series comparing patients on CPAP who switched to MAA \\
\hline$[88]$ & 24 & MAA & 22 & 8 & 70 & - & $\begin{array}{l}\text { Prospective randomized crossover, comparing MAS with CPAP; } \\
\text { soft one-piece mandibular advancement splint }\end{array}$ \\
\hline [89] & 40 & MAA & 50 & 16 & 52 & 28 & $\begin{array}{l}\text { Prospective, randomized, parallel groups comparing } 75 \% \text { and } \\
50 \% \text { of mandibular protrusion; results for } 75 \% \text { group }\end{array}$ \\
\hline$[90]$ & 26 & MAA & 19 & 6 & 73 & 4 & $\begin{array}{l}\text { Prospective, randomized, parallel groups comparing } 75 \% \text { and } \\
50 \% \text { of mandibular protrusion; results for } 75 \% \text { group }\end{array}$ \\
\hline [91] & 25 & MAA & 38 & 15 & 44 & 24 & Case series; The Silencer appliance \\
\hline$[92]$ & 80 & MAA & 21 & 14 & - & - & $\begin{array}{l}\text { Randomized, crossover, controlled, comparing mandibular } \\
\text { advancement splint with CPAP and with placebo tablet }\end{array}$ \\
\hline [93] & 44 & MAA & 46 & 12 & 64 & 18 & Case series; titration protocol; Herbst-like \\
\hline$[94]$ & 19 & MAA & 34 & 17 & 37 & 11 & Case series; titration protocol; Klearway \\
\hline [95] & 277 & MAA & 21 & 8 & 54 & - & Case series; mandibular advancement devices \\
\hline [96] & 11 & MAA & 3 & 2 & - & - & Prospective case series of non-apneic snorers; Herbst; ODI4 \\
\hline [97] & 20 & MAA & 8 & 4 & - & - & Case series; fixed mandibular advancement device \\
\hline [98] & 34 & MAA & 20 & 3 & 94 & 0 & Case series of consecutive patients; TAP appliance \\
\hline [99] & 17 & MAA & 25 & 15 & - & - & Case series of patients with CHF; mandibular advancement device \\
\hline [19] & 19 & MAA & 32 & 8 & 79 & 11 & Case series; Herbst \\
\hline$[100]$ & 16 & MAA & 46 & 24 & - & - & $\begin{array}{l}\text { Prospective, randomized, crossover comparing Twin Block and } \\
\text { Herbst; median AHI }\end{array}$ \\
\hline [101] & 251 & MAA & 29 & 16 & - & - & $\begin{array}{l}\text { Mail survey of } 544 \text { patients; RDI; mainly Klearway, few } \\
\text { mandibular repositioners, fewer TRDs }\end{array}$ \\
\hline [114] & 21 & MAA & 34 & 25 & 5 & 38 & Case series; Klearway appliance \\
\hline [115] & 92 & MAA & 18 & - & - & - & Case series; questionnaires; bed partners' replies recorded \\
\hline
\end{tabular}


Table 2 (continued)

\begin{tabular}{llllllll}
\hline Reference & $N$ & Type & $\mathrm{AHI}_{\text {base }}$ & $\mathrm{AHI}_{\mathrm{appl}}$ & $\begin{array}{l}\text { Success } \\
\text { rate }(\%)\end{array}$ & $\begin{array}{l}\text { Response } \\
\text { rate (\%) }\end{array}$ & Comments \\
\hline$[120]$ & 25 & MAA & 35.9 & 8.2 & 60 & - & Median AHI; case series; 6 weeks use; split polysomnography \\
{$[121]$} & 4 & MAA & 49.5 & 11.7 & 75 & 25 & Case series \\
{$[122]$} & 73 & MAA & 24.4 & 12.2 & 55 & - & Prospective, randomized, placebo-appliance-controlled 4 weeks \\
& & & & & & - & Study \\
{$[123]$} & 12 & MAA & 22 & 9.2 & 58 & 22 & Case series \\
{$[126]$} & 161 & MAA & 18 & 6 & 59 & &
\end{tabular}

The first step in analyzing the results of individual investigations is to decide on which outcome variables to analyze. Since we are interested in sleep apnea, the following four variables are an obvious choice-baseline index of respiration (we shall denote this as $\mathrm{AHI}_{\text {base}}$ ), "with appliance" index of respiration (denoted as $\mathrm{AHI}_{\mathrm{appl}}$ ), success rate defined as the reduction of $\mathrm{AHI}_{\text {base }}$ to a value less than the defining value for sleep apnea, and response rate defined as the reduction of $\mathrm{AHI}_{\text {base }}$ by greater than $50 \%$ while still remaining higher than the defining value for sleep apnea.

Table 2 lists 89 distinct investigations, involving a total of 3,027 patients. Inspection of the individual results indicates the widest possible variability. Respiration is analyzed in terms of AI, ODI4, AHI, or RDI. The definition of sleep apnea was based either on $\mathrm{AI}<5, \mathrm{AHI}<10$, $\mathrm{RDI}<$ 10 or ODI $4<10$. Success and response rates were defined differently in many studies; however, whenever possible we extracted the information to calculate the success and response rates according to the standard definition given above. In other words, no matter what definition of sleep apnea was employed in a particular study, i.e. whether it was defined as $\mathrm{AI}<5, \mathrm{AHI}<10$, or $\mathrm{ODI}<10$, etc. - the success rate we calculated was based on the percent of patients in whom $\mathrm{AHI}_{\mathrm{appl}}$ was less than 10 , and the response rate was calculated as the percent of patients in whom $10<\mathrm{AHI}_{\text {appl }}<0.5 \times \mathrm{AHI}_{\text {base }}$.

Clearly, it is not possible to carry out a meta-analysis of these studies because of the differences in study design, data collection, statistical analysis and presentation of the data. Even the simple descriptive statistics based on the pooled data must be interpreted with caution due to the methodological differences listed above. To obtain the general information about the efficacy of oral appliances, we analyzed the results of individual investigations in several different ways, as follows.

First, we rejected all case reports [24, 29, 31, 48, 52] and all studies, which did not report the mean AI, the mean AHI, or the mean RDI $[43,53,57,64,75,81,96,100$, 120]. These studies reported either the total number of apneas per night, snoring only, median AHI, or ODI4, etc. This procedure left a total of 75 studies involving 2,832 patients. We used this "pooled" data to calculate the "pooled" means for each outcome variable- $\mathrm{AHI}_{\mathrm{base}}$, $\mathrm{AHI}_{\mathrm{appl}}$, success rate and response rate. If an individual study did not report this outcome variable - it was not used in the calculation of pooled means. For example, to calculate the $\mathrm{AHI}_{\text {base, }}$ we only had to reject 1 study [23] where this variable was not reported, thus leaving 74 studies with 2,816 patients. To calculate the $\mathrm{AHI}_{\text {appl }}$, we had to reject 2 studies [23, 115], thus leaving 73 studies with a total of 2,724 patients. Similarly, looking at Table 2, we can easily see which studies had to be rejected to calculate the success and the response rates. The results are shown in Table 3. We note that oral appliance reduced the $\mathrm{AHI}_{\text {base }}$ from 31 to 14 . The success and response rates were $54 \%$ and $21 \%$, respectively.

A second way to analyze the data presented in Table 2 is to select only those investigations where all four outcome variables $\left(\mathrm{AHI}_{\text {base }}, \mathrm{AHI}_{\mathrm{appl}}\right.$, success rate, response rate) were reported. This left 49 studies involving 1,517 patients. It is interesting to note that the results shown in Table 4, are almost identical to what was found in a larger dataset.

A third way to analyze the data is to select only the randomized, crossover, placebo-controlled studies. There are only five such studies - all done after the year 2000 and all using the mandibular advancement appliance. Inactive appliance was used as placebo in four studies [72, 82, 86, 122], and a pill was used as placebo in one study [92]. In the latter study, only the mean AHIs were reported, but not

Table 3 Summary of the outcome variables for studies listed in Table 2

\begin{tabular}{llll}
\hline Variable & Result & No. of patients & No. of studies \\
\hline $\mathrm{AHI}_{\text {base }}$ & 31 & 2,816 & 74 \\
$\mathrm{AHI}_{\text {appl }}$ & 14 & 2,724 & 73 \\
Response rate & $21 \%$ & 1,577 & 51 \\
Success rate & $54 \%$ & 2,087 & 59 \\
\hline
\end{tabular}


Table 4 Summary of results for complete studies

Results for complete studies

No. of studies

No. of patients

1,517

$\mathrm{AHI}_{\text {base }}$

35

$\mathrm{AHI}_{\text {appl }}$

14

Response rate

$20 \%$

Success rate

the success and response rates. The results are shown in Table 5. We note that: (1) only patients with mild to moderate sleep apnea were studied, (2) in two out of five studies, the mean AHI was reduced by less than $50 \%$, (3) the success and response rates differ depending on the cutoff value of the AHI (either five or ten), (4) for $\mathrm{AHI}=10$ cut-off, the success rate is very similar to that of the uncontrolled trials, but the response rate is lower. The overall conclusion from these placebo-controlled crossover trials is that oral appliances significantly improved sleep apnea by reducing $\mathrm{AHI}_{\text {base }}$ from 25 to 14 with the combined success and response rates of $64 \%$.

One of the issues facing the effective use of oral appliances is our ability to determine the appropriate degree of protrusion necessary to resolve apnea and snoring. Until recently, the only way to do so was to advance the mandible forward as much as is tolerated by the patient, to carry out polysomnography and hope that sleep apnea is eliminated. Unlike CPAP, which may be controlled remotely without waking the patient, the design of most appliances requires removing it from patient's mouth to change the degree of protrusion. This wakes up the patient repeatedly, resulting in a high probability that the titration study will be unsuccessful, thus wasting valuable resources. However, several "titration" protocols were described recently to eliminate this problem. Fleury et al. [93] studied a protocol where this titration was done at home, over a period of several weeks, by advancing the mandible in $1 \mathrm{~mm}$ steps and recording symptoms and ODI4. The effective protru-

sion was defined as that which results in either resolution in symptoms or reduction in ODI4 to below ten. Using this protocol, they were able to determine the protrusion, which abolished sleep apnea in $64 \%$ of patients. Tsai et al. [94] described a remotely controlled mandibular advancement device, which could be titrated during the night in much the same way that the CPAP is titrated. The mandible was advanced remotely during the night in $1 \mathrm{~mm}$ increments until respiratory events were eliminated. The success was confirmed subsequently by carrying out all night polysomnography with the oral appliance set to the effective protrusion determined during the titration study. The positive predictive value of this titration protocol was $90 \%$. On the other hand, Kuna et al. [114] found that the titration protocol was not predictive of the response during chronic use. In this investigation, 9 out of 21 patients with OSA achieved reduction in AHI to less than 10 during titration. However, none of them demonstrated the same beneficial response during longer use of the appliance at home with the effective protrusion determined during the titration night. These results indicate that oral appliance titration to predict the amount of mandibular advancement required to reduce $\mathrm{AHI}$ to less than ten is still imprecise and must be used with caution when determining the appliance settings for home use. Nevertheless, the application of titration protocols is a new and important development in this field, which may improve the success of oral appliance therapy by identifying patients who are likely to respond to this treatment.

Predicting who will respond to the oral appliance therapy is not yet possible, although there are several studies where the differences in various parameters (mainly weight and measures of airway size and collapsibility) were studied in responders and non-responders [39, 116, 117]. The best correlates were always weight and oropharyngeal airway size. However, although these studies provide useful information, particularly with respect to the factors that determine airway occlusion, they do not as yet provide us with a method to predict who will respond to this therapy.

Table 5 Summary of results if randomized, crossover, placebo-controlled studies

\begin{tabular}{lllllll}
\hline Reference & $N$ & AHI $_{\text {base }}$ & AHI $_{\text {appl }}$ & Success rate (\%) & Response rate (\%) & Comments \\
\hline$[72]$ & 24 & 30 & 14 & 38 & 25 & For AHI=5 cut-off \\
& & & & 54 & 17 & For AHI=10 cutoff \\
{$[82]$} & 73 & 27 & 12 & 36 & 27 & For AHI=5 cutoff \\
{$[86]$} & 20 & 38 & 23 & 30 & 10 & Identical results for AHI=5 and AHI=10 cutoffs \\
{$[92]$} & 80 & 21 & 14 & - & - & Tablet used as placebo; CPAP arm was also present \\
{$[122]$} & 73 & 24 & 12 & 36 & - & For AHI $=5$ cutoff \\
& & & & 55 & - & For AHI=10 cutoff \\
Summary & 270 & 25 & 14 & 35 & 24 & For AHI=5 cutoff \\
& & & & 50 & 14 & For AHI=10 cutoff \\
\hline
\end{tabular}


Oral appliances vs CPAP

Since CPAP remains as the "gold standard" treatment of sleep apnea, the objective success rate of any other treatment must be judged against it. There are seven randomized, crossover studies, which compared mandibular advancement appliances against CPAP. The results are summarized in Table 6 . We note that the findings of all such studies are remarkably consistent-CPAP results in better improvement in AHI than oral appliances. In all studies except one, CPAP normalized the respiration, bringing AHI to less than ten. In one study where AHI with CPAP remained above ten, the highest pressure used was $10 \mathrm{~cm} \mathrm{H}_{2} \mathrm{O}$, which is probably too low. However, patients subjectively prefer oral appliances over CPAP. In five out of seven studies, the patients expressed preference for an oral appliance, in one study neither treatment was preferred and in another study CPAP was preferred.

There are 2 additional investigations [87, 102], which are not listed in Table 2 because of missing data regarding follow-up sleep study. Nevertheless, these investigations provide interesting information regarding the comparison of oral appliances and CPAP. Smith and Stradling [87] attempted to determine whether oral appliances can substitute CPAP at least for 1 month. The authors found that patients achieved similar reduction in ODI4 with CPAP (from 29 to 1) as with oral appliance (from 29 to 4). However, the patients did not like their oral appliance and were refusing to use it. Out of 50 patients on CPAP who were switched to oral appliance, only 11 were still using it by end of 1 month. Most patients discontinued its use because of discomfort, side effects, or treatment failure. This study therefore favors CPAP. On the other hand, McGown et al. [102] carried out a questionnaire survey of 126 patients treated with oral appliances. There were 41 patients who had tried both CPAP and oral appliance; $71 \%$ preferred oral appliance, $19 \%$ preferred CPAP, and $10 \%$ were unsure. This study favors oral appliance.

We conclude therefore that CPAP is more effective than oral appliances in reducing AHI, but despite this, most patients prefer oral appliances, undoubtedly because they find them to be less cumbersome than CPAP.

Oral appliances vs other treatments

Since 1988 there were several studies $[21,53,59,64,65$, $68,77,79,89,90,100]$, which compared either different types of appliances, different degrees of protrusion or different inter-incisal distance. The results are listed in Table 7. Columns labeled "base" and "appl" show the $\mathrm{AHI}_{\text {base }}$ and $\mathrm{AHI}_{\text {appl }}$, respectively. The column labeled "comp" gives the AHI measured when other, i.e. "comparison" treatment was used. The type of oral appliance employed and the precise variables that were compared are described in the last column. Since most studies employed parallel group design, baseline AHI before comparison treatment is also shown in this column.

Examination of the individual investigations reveals that when oral compliances are compared to each other, either two different appliances or the same appliance with different degrees of protrusion or opening-it is cleat that the efficacy (objective and subjective) is very much dependent on the type of appliance and the degree of advancement. This further emphasizes the point that oral appliance therapy should be carried out by a dentist with expertise in this field who is familiar with different types of appliances and can select the most appropriate one for the particular patient. There is no "best" appliance. The best one is that which is comfortable to the patient and achieves the desired efficacy.

There are several studies, mainly case series, comparing oral appliances with surgical treatments. Comparisons with

Table 6 Randomized, crossover, CPAP vs oral appliance studies

\begin{tabular}{|c|c|c|c|c|c|}
\hline Reference & $N$ & $\mathrm{AHI}_{\text {base }}$ & $\mathrm{AHI}_{\mathrm{appl}}$ & $\begin{array}{l}\text { AHI } \\
\text { CPAP }\end{array}$ & Comments \\
\hline$[46]$ & 19 & 20 & 10 & 4 & $68 \%$ of patients were satisfied with OA vs $62 \%$ with CPAP $(p<0.05)$ \\
\hline$[45]$ & 21 & 34 & 20 & 11 & OA preferred \\
\hline$[50]$ & 20 & 25 & 14 & 4 & $65 \%$ preferred $\mathrm{OA}, 30 \%$ preferred $\mathrm{CPAP}$ \\
\hline$[84]$ & 20 & 18 & 14 & 4 & "Patients identified oral appliance as being easier to use" \\
\hline$[85]$ & 48 & 31 & 15 & 8 & "Neither treatment was significantly preferred by patients" \\
\hline$[88]$ & 24 & 22 & 8 & 3 & "...17 out of the 21 subjects who completed both arms of the study preferred the MAS" \\
\hline$[92]$ & 80 & 21 & 14 & 5 & $\begin{array}{l}\text { "Although subjects reported that CPAP was the most difficult treatment to use, they felt that } \\
\text { it was the most effective and overall preferred it to the MAS, which was in turn preferred } \\
\text { to placebo" }\end{array}$ \\
\hline
\end{tabular}

Summary

$\begin{array}{lllll}232 & 24 & 14 & 6 & \text { Oral appliance preferred overall }\end{array}$


Table 7 Studies comparing oral appliances to treatments other than CPAP

\begin{tabular}{|c|c|c|c|c|c|}
\hline \multirow[t]{2}{*}{ Reference } & \multirow[t]{2}{*}{$N$} & \multicolumn{3}{|l|}{ AHI } & \multirow[t]{2}{*}{ Comments } \\
\hline & & Base & Appl & Comp & \\
\hline [53] & 23 & 4 & 3.5 & 0.8 & $\begin{array}{l}\text { Parallel groups; } \mathrm{OA}=\mathrm{MAA} \text { with } \max \text { protrusion, comp }=\mathrm{MAA} \text { with } 70 \% \text { of maximum protrusion, } \\
\text { but double inter-incisal opening; baseline } \mathrm{AHI}=7 \text { for comp group }\end{array}$ \\
\hline [59] & 41 & 18 & 6 & 10 & $\begin{array}{l}\text { Parallel groups; OA=MAA, comp=UPPP; prospective, randomized, baseline } \mathrm{AHI}=20 \text { for UPPP } \\
\text { group; results at } 12 \text { months }\end{array}$ \\
\hline$[64]$ & 37 & 26 & 17 & 11 & Single group; $\mathrm{OA}=\mathrm{MAA}$ with $2 \mathrm{~mm}$ protrusion, $\mathrm{comp}=6 \mathrm{~mm}$ protrusion; ODI4 recorded \\
\hline$[65]$ & 5 & 50 & 30 & 44 & Single group; $\mathrm{OA}=\mathrm{MAA}, \mathrm{comp}=\mathrm{TRD}$; only $5 / 8$ patients agreed to try TRD \\
\hline$[65]$ & 2 & 47 & 35 & 57 & Single group; comp=SPL; only $2 / 8$ patients agreed to try SPL \\
\hline [68] & 24 & 23 & 9 & 8 & Crossover, randomized; $\mathrm{OA}=\mathrm{MAA}$ (Herbst), comp=monoblock \\
\hline [21] & 10 & 5 & 5 & 10 & Parallel groups: $\mathrm{OA}=\mathrm{TRD}$, comp=somnoplasty; baseline RDI same for both groups \\
\hline [77] & 23 & 21 & 8 & 10 & $\begin{array}{l}\text { Crossover, randomized; OA=MAA with } 4 \mathrm{~mm} \text { inter-incisal opening, comp=MAA with } 14 \mathrm{~mm} \\
\text { opening }\end{array}$ \\
\hline [79] & 72 & 18 & 7 & 14 & $\begin{array}{l}\text { Parallel groups, randomized; OA=MAA, comp=UPPP; baseline } \mathrm{AHI} \text { for UPPP group=20; results } \\
\text { at } 4 \text { years }\end{array}$ \\
\hline [89] & 84 & 47 & 17 & 16 & $\begin{array}{l}\text { Parallel groups, randomized; OA=MAA with } 50 \% \text { protrusion, comp=MAA with } 75 \% \text { protrusion; } \\
\text { baseline AHI for } 75 \% \text { group }=50 \text {; results at } 6 \text { months }\end{array}$ \\
\hline [90] & 55 & 16 & 6 & 6 & $\begin{array}{l}\text { Parallel groups, randomized; OA=MAA with } 50 \% \text { protrusion, comp=MAA with } 75 \% \text { protrusion; } \\
\text { baseline AHI for } 75 \% \text { group }=19 \text {; results at } 12 \text { months }\end{array}$ \\
\hline [100] & 16 & 46 & 25 & 34 & Crossover, prospective, randomized; OA=Herbst, comp=Twin Block; median AHIs reported \\
\hline \multicolumn{6}{|l|}{ Summary } \\
\hline & 392 & 26 & 11 & 12 & \\
\hline
\end{tabular}

UPPP [59, 79] demonstrated the superiority of oral appliances. At 1 year follow-up, sleep apnea was resolved $(\mathrm{AHI}<10)$ in $78 \%$ of the oral appliances group and $51 \%$ of the UPPP group. With longer follow-up, this success rate deteriorates. At 4 years follow-up, $63 \%$ of the oral appliance group and $33 \%$ of the UPPP group continue to have $\mathrm{AHI}<10$. One parallel group study of oral appliance (TRD) vs radiofrequency ablation (somnoplasty) found that both treatments significantly reduced sleep time spent with loud snoring. However, there was no difference between oral appliance and somnoplasty [21]. A recent small case series of 4 patients (out of 43 treated with oral appliances) who elected maxillomandibular advancement surgery [121] showed that initial $\mathrm{AHI}=50$ dropped to 12 with oral appliance and to 2 after surgery.

\section{Oral appliances for the treatment of snoring}

Although everyone can recognize snoring, it proved to be a very elusive entity to measure objectively. One can define the sound properties (i.e. frequency spectrum and intensity), relationship to breathing (i.e. waxing and waning sound, generally during inspiration), and measure this sound during sleep. However, subjective recognition of sound, which satisfies some pre-defined "snoring" criteria as de facto snoring depends very much on the listener. This is contrary to the case of apneas or even hypopneas, whose definition is independent of any subjective perception. These difficulties with the definition of snoring are the reasons why objective measurement of sound is seldom a routine part of polysomnography. However, snoring is the cardinal symptom of sleep apnea. In fact, it is frequently the only reason why these patients come to the sleep clinic in the first place. Consequently, when polysomnography does not reveal sleep apnea in these patients, the physician still has to deal with their snoring. Unfortunately, this is often ignored by physicians.

The most frequent scenario is that a patient is referred to a sleep specialist because of snoring, polysomnography is carried out, no sleep apnea is found, the patient is reassured, advised to loose weight, stop smoking and drinking alcohol, embark on an exercise program, and discharged from the clinic. Sometimes this advice, dispensed in the form of preprinted sheets, is given also to non-obese nonsmokers. Clearly, the patient leaves unhappy, the referring physician is dissatisfied with the help received from the specialist and nothing was accomplished to justify the expense incurred in the process of investigations. For apneic snorers, the problem is simpler because treatment with CPAP will abolish snoring.

Non-apneic snorers without daytime symptoms do not tolerate CPAP well. Many of them will agree to try it, but the majority will stop using it after a short time (generally a few weeks to a few months). Oral appliances therefore constitute an attractive alternative for the treatment of 
snoring. In fact, they were originally invented precisely for that reason.

Many, but not all investigations of oral appliances comment on their efficacy in reducing snoring. Recognizing that the objective measurement of sound during polysomnography may not correspond to the perception of this sound as being snoring-subjective assessment is generally employed. This assessment varies from simply asking an informal question "is your snoring improved?", to employing a more formal method, which is usually a visual scale (analogue or digital) to rate snoring. Unfortunately, in almost all studies, the answers to these subjective questions are given by the snorers who of course are unaware of their snoring, rather than by the bed partner. Although snoring is recorded as the patient's chief complaint, it is really not the patient's complaint at all-it is the complaint of the bed partner. The implicit assumption in most investigations is that the patient's responses reflect those of the bed partner. Nevertheless, the efficacy of snoring treatment must be assessed by the same bed partner, not by the snorer. This poses great logistical problems in carrying out appropriate investigations. However, some support for this assumption of equivalence between the responses of snorers and listeners is provided by a recent questionnaire data of Bates and McDonald [115] who found that $70 \%$ of snorers and $70 \%$ of the bed partners reported improvement in snoring after using a mandibular repositioning splint for 3 months.

Table 8 lists 47 investigations, which utilized oral appliances. The only common feature among these investigations, and the reason why other investigations were not included - is that all of the listed ones contained a specific comment regarding snoring. The types of snoring assessment carried out in these investigations ranged from an informal question about snoring to rating the snoring using a visual scale and objective sound measurement together with subjective assessment. Very few investigations included objective measurement of snoring. Investigations with subjective assessment of snoring using questionnaires form a very inhomogeneous group because they used different types of questionnaires with different rating methods. Given these differences in methodology, it is not possible to rigorously summarize the results. However, certain generalizations can be made.

First, the majority of the investigations concluded that oral appliances are beneficial in reducing snoring in the majority of patients. Second, all of the randomized, placebo-appliance-controlled studies except one [86] found significant reduction in snoring, independently of whether it was assessed objectively or subjectively. Johnston et al. [86] did not find a significant difference in either the loudness (measured using the VAS 0 to 5 scale) or the frequency (nights/week) of snoring. However, an earlier study from the same group [75], employing similar methodology but different patient population (non-apneic snorers), did demonstrate significant reduction in snoring. This further illustrates the difficulties with subjective assessment of snoring in different patient populations. Even in the same patient population, there is a discrepancy between objective measurement and subjective perception, as found by Lawton et al. [100].

We shall present the summary of the individual investigations listed in Table 8 as follows. First, we selected only those investigations where a numerical value describing snoring with and without appliance was given. These results are shown in Table 9. There are 18 studies involving 529 patients. All, except one [21], employed the mandibular adjustment appliance. All of these investigations give a "number" to quantify snoring. We note the diversity of measurement of snoring in each study - the "number" in Table 9 represents either a VAS score, number of snorers/h (or min) of sleep, amount of time spent with loud snoring per hour of sleep or per night, number of nights per week spent with disturbing snoring or noise level, etc. However, we can calculate the percent change between the baseline night and the "with appliance" night, displayed in the last column of Table 9. We note that despite the diversity of snoring measurements, in all investigations the percent change is negative - which indicates that the investigators always found reduction in snoring with oral appliances. The mean reduction in snoring using the pooled data was $45 \%$.

\section{Effect of oral appliances on daytime function}

In assessing the effect of oral appliances on sleep apnea syndrome, it is not sufficient to focus only on the apnea/ hypopnea index or snoring. We must also demonstrate the effect of this treatment on daytime function, which is almost always compromised in patients with sleep apnea and sometimes in non-apneic snorers also. There are several tools used to assess daytime function, but there is little consistency in using these tools in investigations involving oral appliances.

Table 10 summarizes the results of investigations where some assessment of daytime function was performed, no matter how primitive. The methods of assessment differ in each investigation. Some relied on answers to questions regarding daytime sleepiness and tiredness, others utilized visual scales, yet other investigations measured response time to various tasks, etc. After 1995, the majority of investigations employed the Epworth sleepiness score (ESS). The results generally show improvement in daytime symptoms with oral appliances.

Because of the diversity of methods assessing daytime function, it is difficult to pool and summarize the individual data. One way of doing this is to select only those 
Table 8 Snoring

\begin{tabular}{|c|c|c|c|c|c|}
\hline \multirow[t]{2}{*}{ Reference } & \multirow[t]{2}{*}{$N$} & \multirow[t]{2}{*}{ Type } & \multicolumn{2}{|c|}{$\begin{array}{l}\text { Snoring } \\
\text { measure }\end{array}$} & \multirow[t]{2}{*}{ Comments } \\
\hline & & & Base & Appl & \\
\hline$[27]$ & 5 & TRD & & & "Snoring decreased or completely disappeared" \\
\hline [28] & 12 & MAA & & & "8/12 reported substantial reduction of sonorous sleeping \\
\hline [31] & 1 & MAA & & & "After appliance insertion...immediate...reduction in snoring" \\
\hline$[34]$ & 68 & MAA & 8.5 & 1.5 & Snoring severity assessed subjectively $(\max$ score $=10$ ); snoring eliminated in $42 \%$ \\
\hline$[35]$ & 12 & MAA & & & Snoring reduced, although never eliminated, in $79 \%$ \\
\hline [38] & 24 & MAA & 7.6 & & Snoring on a scale from 0 to 10 ; improvement also on a scale from 0 to 10 -result $=4.3$ \\
\hline$[42]$ & 51 & MAA & 9.4 & 8.2 & No. of snores/min; snoring eliminated in $8 / 51$, improved in $43 / 51$ \\
\hline$[46]$ & 25 & MAA & & & Snoring less than "moderate" in $19 / 25$ pts \\
\hline$[47]$ & 23 & MAA & & & “...20/23 patients $(87 \%)$ reported subjective improvement...in snoring” \\
\hline$[49]$ & 23 & TRD & & & "Visual analog scores of snoring...were also reduced significantly" in $6 / 23(23 \%)$ subjects \\
\hline [53] & 23 & MAA & & & "...loud snore duration was reduced from a median of $27.1 \mathrm{~min}$ to $11.4 \mathrm{~min}$ " \\
\hline$[54]$ & 44 & MAA & & & "Snoring was satisfactorily reduced in" $37 / 44$ patients $(84 \%)$ \\
\hline$[57]$ & 15 & MAA & 193 & 20 & Median snores/h given; snoring loudness and time spent snoring also improved \\
\hline [102] & 132 & MAA & & & "Snoring was reported...to be satisfactorily controlled in $107(81 \%) \ldots$ \\
\hline$[58]$ & 14 & MAA & & & $6 / 14$ - no snoring; $8 / 14$ — mild snoring \\
\hline [59] & 41 & MAA & 0.7 & 0.5 & No. of snores/h of sleep at baseline and 12 months follow-up (NS) \\
\hline$[60]$ & 75 & MAA & & & "Dramatic reduction in the attributes of snoring was achieved" \\
\hline$[66]$ & 112 & MAA & & & $76 / 112(68 \%)$ snoring either eliminated or acceptable \\
\hline [68] & 24 & MAA & 50 & 33 & $\begin{array}{l}\text { No of snores/h sleep; results for Herbst appliance; } 19 / 20 \text { disturbed by snoring at baseline, vs } 9 / 20 \\
\text { with appliance }\end{array}$ \\
\hline$[21]$ & 10 & TRD & 11 & 3 & Percent of time spent in loud snoring \\
\hline$[69]$ & 39 & MAA & & & "Time with snoring dropped significantly from $16.3 \%$ to $6.6 \% "$ \\
\hline [71] & 22 & MAA & & & Snoring eliminated in $13 / 22$, significantly reduced in $5 / 22$; success rate $=18 / 22(82 \%)$ \\
\hline$[104]$ & 53 & MAA & & & Questionnaire survey; $27 / 53$ were still using the device at 1 year, and 22 were satisfied ( $42 \%)$ \\
\hline$[105]$ & 21 & MAA & & & $\begin{array}{l}\text { Questionnaire survey; } 22 \text { patients fitted with appliance; } 43 \% \text { thought it reduced snoring, } 48 \% \text {-no } \\
\text { benefit }\end{array}$ \\
\hline [102] & 126 & MAA & & & Questionnaire survey; "80 out of 94 patients reported improvement in snoring" \\
\hline [73] & 22 & MAA & 59 & 24 & No. of snores/h of sleep; subjective improvement as well \\
\hline [75] & 25 & MAA & 3.4 & 1.8 & $\begin{array}{l}\text { Randomized controlled vs placebo-appliance; non-apneic snorers; frequency of snoring (nights/ } \\
\text { week), } p<0.05 ; 15 / 25 \text { greatly improved with MAA vs } 2 / 25 \text { with placebo }\end{array}$ \\
\hline [76] & 33 & MAA & & & "19/33 had short-term satisfactory treatment results with the device" \\
\hline [72] & 28 & MAA & 402 & 242 & $\begin{array}{l}\text { Randomized, controlled vs placebo-appliance; snores/h of sleep }(p<0.005) \text {; mean snoring intensity } \\
\text { significantly reduced; "the majority of patients reported substantial improvement in snoring }(70 \%)\end{array}$ \\
\hline [82] & 73 & MAA & 366 & 207 & $\begin{array}{l}\text { Randomized, controlled vs placebo-appliance; snores/h of sleep }(p<0.0001) \text {; mean and maximum } \\
\text { snoring intensity significantly reduced; significant subjective reduction in snoring }\end{array}$ \\
\hline [86] & 16 & MAA & 3.1 & 2.6 & $\begin{array}{l}\text { Randomized, placebo-controlled crossover; frequency of snoring (nights/week) ( } p=0.07) \text {; no } \\
\text { significant difference in loudness of snoring }\end{array}$ \\
\hline [79] & 32 & MAA & 0.7 & 0.5 & Duration of snoring $/ \mathrm{h}$ of sleep $(p<0.01)$ \\
\hline$[80]$ & 26 & MAA & & & "The patients and their bed partners thought that...snoring...improved..." \\
\hline$[84]$ & 20 & MAA & 55 & 36 & Snoring epochs $/ \mathrm{h}(p<0.01)$; randomized crossover study vs CPAP \\
\hline [89] & 40 & MAA & 0.86 & 0.57 & $\begin{array}{l}\text { Duration of snoring } / \mathrm{h} \text { of sleep }(p<0.001) \text {; comparison of two protrusions; results for } 75 \% \\
\text { protrusion group }\end{array}$ \\
\hline$[90]$ & 26 & MAA & & & $\begin{array}{l}\text { Comparison of two protrusions; results for } 75 \% \text { protrusion group; "problems with apneas and } \\
\text { snoring...decreased by...79\%..." }\end{array}$ \\
\hline [91] & 25 & MAA & & & $\begin{array}{l}\text { "...snoring...patients have benefited from oral appliance therapy and their spouses will testify to the } \\
\text { same" }\end{array}$ \\
\hline [93] & 44 & MAA & & & $\begin{array}{l}\text { Subjective assessment; "on average, a mean reduction of } 90 \% \text { of the intensity of snoring was } \\
\text { reported by the patients" }\end{array}$ \\
\hline [95] & 619 & MAA & & & $\begin{array}{l}\text { "It is estimated that } 50 \% \text { of the } 619 \text { snorers and sleep apnea patients had treatment success or } \\
\text { subjective beneficial effects..." }\end{array}$ \\
\hline [96] & 11 & MAA & 240 & 75 & $\begin{array}{l}\text { Noise level measured; "10 out of } 11 \text { subjects had a significant reduction in snore noise sound } \\
\text { level..." }\end{array}$ \\
\hline [97] & 20 & MAA & 9.0 & 6.8 & VAS $0-10$ scale $(p<0.05)$; result at 6 months follow-up; subjectively $14 / 20$ were satisfied \\
\hline [106] & 110 & MAA & & & Questionnaire survey; 37 out of 77 patients who returned questionnaire thought snoring was \\
\hline
\end{tabular}


Table 8 (continued)

\begin{tabular}{|c|c|c|c|c|c|}
\hline \multirow[t]{2}{*}{ Reference } & \multirow[t]{2}{*}{$N$} & \multirow[t]{2}{*}{ Type } & \multicolumn{2}{|c|}{$\begin{array}{l}\text { Snoring } \\
\text { measure }\end{array}$} & \multirow[t]{2}{*}{ Comments } \\
\hline & & & Base & Appl & \\
\hline & & & & & satisfactorily controlled \\
\hline [99] & 17 & MAA & 53 & 16 & $p=0.02 ;$ snoring time \\
\hline [19] & 25 & MAA & & & $15 / 25$ snoring markedly improved \\
\hline$[100]$ & 16 & MAA & 144 & 64 & Snores/h; however, VAS 0-10 scale-no difference \\
\hline$[101]$ & 251 & MAA & & & $\begin{array}{l}75 \% \text { of } 191 \text { users of appliance reported control of snoring; } 43 \% \text { of non-users of appliance also } \\
\text { thought snoring was controlled }\end{array}$ \\
\hline$[115]$ & 53 & MAA & & & Snoring was reported to be improved by $70 \%$ of the responding bed partners \\
\hline
\end{tabular}

investigations, which employed identical methods of assessment and summarize the mean results, as was done in the previous tables. The most common single way of assessing daytime function in most investigations was the ESS. These investigations are listed in Table 11. There are 23 of them involving a total of 962 patients. However, not all investigations could be used in calculating pooled data. We rejected four investigations [19, 53, 98, 100], involving 108 patients where only the median and not the mean values of the ESS were reported. Consequently, we are left with 19 investigations involving 854 patients. As a group, these patients were only mildly sleepy with the mean ESS of 11.2. In all investigations, the ESS dropped with the use of oral appliances. For the entire group, there was a significant reduction in the ESS from 11.2 to 7.8 .
In two investigations $[85,86]$, both randomized, crossover and controlled (one vs placebo and another one vs CPAP) reduction in ESS was not significant. Engleman et al. [85] carried out a very extensive study of daytime function comparing the effect of oral appliance to CPAP. Functional assessment included maintenance of wakefulness test, measures of daytime sleepiness and symptoms, measures of well-being (using the SF-36 questionnaire, HADS anxiety and depression score), and cognitive performance. The results favored CPAP in 7 out of 21 variables (including the ESS, AHI, effectiveness and symptoms), and showed no difference between CPAP and oral appliance in other variables (including the maintenance of wakefulness tests, cognitive performance and treatment preference). Johnston et al. [75, 86] compared oral

Table 9 Studies with measurement of snoring

\begin{tabular}{|c|c|c|c|c|c|}
\hline \multirow[t]{2}{*}{ Reference } & \multirow[t]{2}{*}{$N$} & \multicolumn{2}{|c|}{ Snoring measure } & \multirow[t]{2}{*}{ Explanation of snoring measurement } & \multirow[t]{2}{*}{ Percent change } \\
\hline & & Base & Appl & & \\
\hline$[34]$ & 68 & 8.5 & 1.5 & Visual analogue scale $0-10$ & -82 \\
\hline$[42]$ & 51 & 9.4 & 8.2 & Number of snores/min & -13 \\
\hline$[57]$ & 15 & 193 & 20 & Number of snores $/ \mathrm{h}$ & -90 \\
\hline$[59]$ & 41 & 0.7 & 0.5 & Number of snores $/ \mathrm{h}$ & -29 \\
\hline$[68]$ & 24 & 50 & 33 & Number of snores $/ \mathrm{h}$ & -34 \\
\hline$[21]$ & 10 & 11 & 3 & Percent of sleep time spent in loud snoring & -73 \\
\hline$[73]$ & 22 & 59 & 24 & Number of snores $/ \mathrm{h}$ & -59 \\
\hline$[75]$ & 25 & 3.4 & 1.8 & Nights/per week with disturbing snoring & -47 \\
\hline$[72]$ & 28 & 402 & 242 & Number of snores $/ \mathrm{h}$ & -40 \\
\hline [82] & 73 & 366 & 207 & Number of snores $/ \mathrm{h}$ & -43 \\
\hline$[86]$ & 16 & 3.1 & 2.6 & Nights/per week with disturbing snoring & -16 \\
\hline [79] & 32 & 0.7 & 0.5 & Minutes of snoring $/ \mathrm{h}$ of sleep & -29 \\
\hline$[84]$ & 20 & 55 & 36 & Snoring epochs $/ \mathrm{h}$ of sleep & -35 \\
\hline [89] & 40 & 0.86 & 0.57 & Minutes of snoring $/ \mathrm{h}$ of sleep & -34 \\
\hline$[96]$ & 11 & 240 & 75 & Noise level & -69 \\
\hline$[97]$ & 20 & 9.0 & 6.8 & Visual analogue scale $0-10$ & -24 \\
\hline [99] & 17 & 53 & 16 & Total snoring time & -66 \\
\hline$[100]$ & 16 & 144 & 64 & Number of snores/h of sleep & -56 \\
\hline \multirow[t]{2}{*}{ Summary } & & & & & \\
\hline & 529 & & & & -45 \\
\hline
\end{tabular}


Table 10 Functional assessment

\begin{tabular}{|c|c|c|c|c|c|}
\hline \multirow[t]{2}{*}{ Reference } & \multirow[t]{2}{*}{$N$} & \multirow[t]{2}{*}{ Test or question } & \multicolumn{2}{|c|}{ Result } & \multirow[t]{2}{*}{ Comments } \\
\hline & & & Base & Appl & \\
\hline$[11]$ & 14 & Daytime function & - & - & $14 / 14$ reported improvement \\
\hline$[25]$ & 7 & Sleepiness & - & - & Improved \\
\hline$[26]$ & 44 & Vigilance & 0.5 & 0.4 & Reaction time $(p<0.05)$ \\
\hline$[27]$ & 5 & Daytime sleepiness & - & - & "Daytime somnolence was eliminated or diminished markedly" \\
\hline$[28]$ & 12 & Daytime somnolence & - & - & $\begin{array}{l}\text { "9/12 patients reported increased alertness and/or reduction in daytime } \\
\text { sleepiness" }\end{array}$ \\
\hline$[34]$ & 63 & $\begin{array}{l}\text { Prevalence of daytime } \\
\text { sleepiness }\end{array}$ & - & - & " $51 \%$ of these patients reported no more sleepiness with orthosis use" \\
\hline$[35]$ & 12 & Daytime sleepiness & - & - & "Daytime sleepiness was improved...in all but two patients" \\
\hline$[33]$ & 14 & $\begin{array}{l}\text { Symptom score (including } \\
\text { sleepiness) }\end{array}$ & 5.5 & 1.1 & Significant $(p<0.001)$ improvement in daytime symptoms \\
\hline$[38]$ & 24 & $\begin{array}{l}\text { Sleepiness and } \\
\text { improvement using } 0-10 \\
\text { Likert scale }\end{array}$ & 6.4 & - & Improvement on $0-10$ Likert scale $=4.5$ at 36 months \\
\hline$[42]$ & 51 & $\begin{array}{l}\text { Patients tired; patients } \\
\text { sleepy }\end{array}$ & 44 & 30 & \\
\hline$[44]$ & 30 & $\begin{array}{l}\text { No. of mistakes in vigilance } \\
\text { test }\end{array}$ & 7.6 & 3.7 & $p<0.05$ \\
\hline$[45]$ & 21 & EDS daytime symptoms & 2.4 & 1.6 & $1-5$ scale; $p<0.0001)$ for all symptoms \\
\hline$[46]$ & 25 & Prevalence of EDS & $84 \%$ & $40 \%$ & $p<0.005$; significant reduction in prevalence of other symptoms \\
\hline [47] & 23 & Patients with EDS & 23 & 20 & \\
\hline [49] & 14 & EDS using VAS & - & - & $\begin{array}{l}\text { Reduction in scores }(p<0.05) \text { in } 6 \text { of } 14 \text { patients who were compliant with } \\
\text { treatment }\end{array}$ \\
\hline$[50]$ & 20 & ESS & 10.3 & 4.7 & $p<0.05$; EDS improved in $13 / 20$ patients \\
\hline$[53]$ & 14 & ESS & 12 & 4.5 & Median score, $p<0.005$ \\
\hline$[53]$ & 9 & ESS & 7 & 4 & Median score, $p<0.005$ \\
\hline$[54]$ & 44 & $\begin{array}{l}\text { Patients with daytime } \\
\text { sleepiness }\end{array}$ & 44 & 34 & \\
\hline$[58]$ & 14 & $\begin{array}{l}\text { Patients with moderate and } \\
\text { severe daytime } \\
\text { somnolence }\end{array}$ & 10 & 0 & \\
\hline$[59]$ & 41 & $\begin{array}{l}\text { Daytime sleepiness on } 1-5 \\
\text { scale }\end{array}$ & - & - & $\begin{array}{l}\text { Prospective, randomized, UPPP group and OA group; "in comparison } \\
\text { with their baseline values...a significant }(p<0.001) \text { reduction in } \\
\text { subjective daytime sleepiness" }\end{array}$ \\
\hline$[60]$ & 75 & ESS & 11 & 7 & $p<0.0005$ \\
\hline [107] & 90 & $\begin{array}{l}\text { Quality of life (vitality+ } \\
\text { contentment+sleep) }\end{array}$ & 129 & 94 & $\begin{array}{l}\text { Significant improvement compared to baseline; two parallel groups-OA } \\
\text { vs UPPP; no difference in vitality and sleep }\end{array}$ \\
\hline$[66]$ & 112 & $\begin{array}{l}\text { No. of patients "refreshed } \\
\text { by sleep" }\end{array}$ & - & $66 / 114$ & $\begin{array}{l}\text { "Most of the regular users had an improvement in their quality of sleep } \\
\text { and day time somnolence..." }\end{array}$ \\
\hline$[68]$ & 24 & ESS & 13.1 & 8.6 & $p<0.001$; identical result for two different MAAs \\
\hline$[71]$ & 22 & $\begin{array}{l}\text { No. of patients whose } \\
\text { sleepiness disappeared }\end{array}$ & & $17 / 22$ & $\begin{array}{l}\text { "17 ( } 85 \%) \text { of } 22 \text { patients reported subjective improvement in excessive } \\
\text { daytime sleepiness" }\end{array}$ \\
\hline$[72]$ & 24 & ESS & 10.1 & 3.9 & $p<0.01$ \\
\hline [73] & 22 & ESS & 12 & 7.5 & $p<0.05$ at 12 to 30 months follow-up \\
\hline$[75]$ & 24 & ESS & 7.5 & 6.5 & $p<0.01$; randomized placebo-controlled crossover trial of non-apneic snorers \\
\hline$[76]$ & 19 & $\begin{array}{l}\text { No. of patients reporting } \\
\text { reduction in EDS }\end{array}$ & & $13 / 19$ & \\
\hline [77] & 23 & ESS & 18 & 12 & $p<0.0001$; identical result for two different MAAs \\
\hline [81] & 26 & Questionnaire: EDS & & 1.61 & Scale from -3 (maximum deterioration) to +3 (maximum improvement) \\
\hline [87] & 34 & ESS & 13 & 7.7 & $\begin{array}{l}\text { After } 28 \text { days, only } 11 \text { patients continued to wear MAA; initial ESS based } \\
\text { on } 34 \text { patients, final-on } 11\end{array}$ \\
\hline$[88]$ & 24 & ESS & 13.4 & 9.0 & $p<0.001$; randomized crossover vs CPAP \\
\hline$[85]$ & 48 & ESS & 14 & 12 & $\begin{array}{l}\text { NS; randomized crossover vs CPAP; extensive tests of daytime function; } \\
\text { "these results do not support these MRS devices as first-line treatment } \\
\text { for sleepy patients with SAHS" }\end{array}$ \\
\hline
\end{tabular}


Table 10 (continued)

\begin{tabular}{|c|c|c|c|c|c|}
\hline \multirow[t]{2}{*}{ Reference } & \multirow[t]{2}{*}{$N$} & \multirow[t]{2}{*}{ Test or question } & \multicolumn{2}{|c|}{ Result } & \multirow[t]{2}{*}{ Comments } \\
\hline & & & Base & Appl & \\
\hline [82] & 73 & ESS & 11 & 9 & $\begin{array}{l}p<0.0001) \text {; "the proportion of patients with normal subjective sleepiness } \\
\text { was significantly higher with the MAS than with the control device ( } 82 \\
\text { vs } 62 \%, p<0.01 \text { ), but this was not so for objective sleepiness ( } 48 \% \text { vs } \\
34 \%, p=0.08) \text { " }\end{array}$ \\
\hline [86] & 18 & ESS & 12.6 & 11.6 & NS; randomized placebo-controlled crossover trial of apneic snorers \\
\hline [89] & 42 & ESS & 11.5 & 7.5 & $\begin{array}{l}p<0.001 \text {; prospective randomized comparing } 50 \% \text { and } 75 \% \text { protrusion; } \\
\text { result for } 75 \% \text {; initial value - } 42 \text { patients, final value }-40\end{array}$ \\
\hline [90] & 55 & Questionnaire: EDS & & & $\begin{array}{l}\text { Randomized comparison of two protrusions; " } 82 \% \text { of patients in } 50 \% \\
\text { group }(n=29) \text { and } 84 \% \text { in } 75 \% \text { group }(n=26) \text { reported a decrease in } \\
\text { daytime sleepiness" }\end{array}$ \\
\hline [96] & 29 & ESS & 9.4 & 6.9 & $p<0.001$ \\
\hline [92] & 80 & ESS & 10.2 & 9.2 & $p<0.001$; randomized vs placebo pill and CPAP \\
\hline [93] & 40 & ESS & 12.0 & 5.1 & $p<0.001$ \\
\hline [97] & 20 & ESS & 8.8 & 5.4 & $p<0.05$ \\
\hline [98] & 42 & ESS & 10 & 6 & $p<0.02$; median values \\
\hline [19] & 27 & ESS & 9 & 6 & $p<0.001$; median values \\
\hline$[100]$ & 16 & ESS & 10 & 8 & Median values \\
\hline$[101]$ & 161 & ESS & 11 & 7 & In users of OA; in 90 non-users-ESS fell from 11.1 to 8.1 \\
\hline [115] & 67 & $\begin{array}{l}\text { Concentration, energy } \\
\text { levels, sleep quality, ESS }\end{array}$ & 9.7 & - & ESS given; $29-59 \%$ of responders reported improvement \\
\hline [122] & 73 & $\begin{array}{l}\text { ESS and full battery of } \\
\text { neuropsychological } \\
\text { measures }\end{array}$ & 5.0 & 4.2 & $\begin{array}{l}\text { Total score of all self-report measures given; prospective, randomized, } \\
\text { placebo-appliance-controlled } 4 \text { weeks study }\end{array}$ \\
\hline
\end{tabular}

appliance to placebo, but did not carry extensive investigations of daytime function-only the ESS and a 5-point scale describing how refreshed the patients felt in the morning. The authors found significant improvement compared to placebo, but only in non-apneic snorers [75], not in patients with sleep apnea [86].

In all other randomized, crossover, controlled studies there was a statistically significant improvement in the ESS, but not in other subjective measures of daytime performance. In fact, none of the studies demonstrated a significant improvement in all of the subjective outcomes studied. This is not surprising because almost all studies comparing placebo treatment with active treatment, no matter what it is, always demonstrate a significant placebo effect.

Probably the most complete assessment of neuropsychological function was carried out by Naismith et al. [122] in a prospective, randomized, placebo-appliance-controlled study of 73 patients treated for 4 weeks. The authors demonstrated significant improvement in the measures of self-reported sleepiness, fatigue and energy levels, but no improvement in the measured speed/vigilance (except for the improved reaction time), attention/working/verbal memory or visuospatial/executive functioning. Walker-Engstrom et al. [107] compared the quality of life in two parallel groups of patients with sleep apnea 1 year after treatment with either oral appliance or UPPP. The ESS was not measured, but there was other extensive assessment of three quality of life dimensions (vitality, contentment and sleep). Both groups improved compared to the baseline. There was no difference in vitality and sleep dimensions between the two groups, but the UPPP group was more content than the oral appliance group.

The effect of oral appliances on daytime function was not studied as fully and extensively as for CPAP. For example, there are no studies comparing driving simulator performance in patients treated with oral appliance, no studies comparing multiple sleep latency or maintenance of wakefulness. Recognizing the limited nature of the datathe conclusion from all of the investigations taken as a group must be that oral appliances improve daytime function, although they are not necessarily superior or consistently preferred than other treatments such as CPAP and UPPP.

\section{Effect of oral appliances on vascular disease}

Numerous investigations examined the relationship between sleep apnea and vascular events, such as coronary artery disease, hypertension, and cerebro-vascular disease. Fewer, but still many investigations were carried out to 
Table 11 Functional assessment using ESS

\begin{tabular}{|c|c|c|c|c|}
\hline \multirow[t]{2}{*}{ Reference } & \multirow[t]{2}{*}{$N$} & \multicolumn{2}{|l|}{ ESS } & \multirow[t]{2}{*}{ Comments } \\
\hline & & Base & Appl & \\
\hline$[50]$ & 20 & 10.3 & 4.7 & $p<0.05$; EDS improved in $13 / 20$ patients \\
\hline$[53]$ & 14 & 12 & 4.5 & Median score, $p<0.005$ \\
\hline$[53]$ & 9 & 7 & 4 & Median score, $p<0.005$ \\
\hline$[60]$ & 75 & 11 & 7 & $p<0.0005$ \\
\hline$[68]$ & 24 & 13.1 & 8.6 & $p<0.001$; identical result for two different MAAs; \\
\hline$[72]$ & 24 & 10.1 & 3.9 & $p<0.01$ \\
\hline$[73]$ & 22 & 12 & 7.5 & $p<0.05$ at 12 to 30 months follow-up \\
\hline$[75]$ & 24 & 7.5 & 6.5 & $p<0.01$; randomized placebo-controlled crossover trial of non-apneic snorers \\
\hline [77] & 23 & 18 & 12 & $p<0.0001$; identical result for two different MAAs \\
\hline [87] & 34 & 13 & 7.7 & After 28 days, only 11 patients continued to wear MAA; initial ESS based on 34 patients, final ESS — on 11 \\
\hline [88] & 24 & 13.4 & 9.0 & $p<0.001$; randomized crossover vs CPAP \\
\hline$[85]$ & 48 & 14 & 12 & $\begin{array}{l}\text { NS; randomized crossover vs CPAP; extensive tests of daytime function; "these results do not support these } \\
\text { MRS devices as first-line treatment for sleepy patients with SAHS" }\end{array}$ \\
\hline$[82]$ & 73 & 11 & 9 & $\begin{array}{l}p<0.0001) \text {; "the proportion of patients with normal subjective sleepiness was significantly higher with the } \\
\text { MAS than with the control device ( } 82 \% \text { vs } 62 \%, p<0.01) \text {, but this was not so for objective sleepiness ( } 48 \% \\
\text { vs } 34 \%, p=0.08 \text { ) }\end{array}$ \\
\hline$[86]$ & 18 & 12.6 & 11.6 & NS; randomized placebo-controlled crossover trial of apneic snorers \\
\hline$[89]$ & 42 & 11.5 & 7.5 & $\begin{array}{l}p<0.001 \text {; prospective randomized comparing } 50 \% \text { and } 75 \% \text { protrusion; result for } 75 \% \text {; initial } n=42 \\
\text { patients, final } n=40 \text { patients }\end{array}$ \\
\hline [96] & 29 & 9.4 & 6.9 & $p<0.001)$ \\
\hline [92] & 80 & 10.2 & 9.2 & $p<0.001$; randomized vs placebo pill and CPAP \\
\hline [93] & 40 & 12.0 & 5.1 & $p<0.001$ \\
\hline [97] & 20 & 8.8 & 5.4 & $p<0.05$ \\
\hline [98] & 42 & 10 & 6 & $p<0.02$; median values \\
\hline [19] & 27 & 9 & 6 & $p<0.001$; median values \\
\hline$[100]$ & 16 & 10 & 8 & Median values \\
\hline$[101]$ & 161 & 11 & 7 & Result for users of OA; in 90 non-users-ESS fell from 11.1 to 8.1 \\
\hline [122] & 73 & 9.1 & 7.1 & Prospective, randomized, placebo-appliance-controlled 4 weeks study \\
\hline \multicolumn{5}{|r|}{ 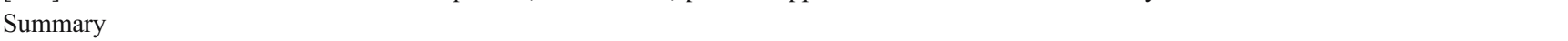 } \\
\hline & 854 & 11.2 & 7.8 & References $19,53,98-100$ were excluded (no mean values were given) \\
\hline
\end{tabular}

examine the effect of the treatment of sleep apnea with CPAP on changes in these conditions.

Quite the opposite situation is seen regarding the effect of oral appliances on vascular disease. There are only three studies examining the effect of the treatment of sleep apnea with oral appliance on blood pressure. Both studies employed the randomized, controlled, crossover design. The first study was carried out by Gotsopoulos et al. [113] specifically for the purpose of examining the effect of 4 weeks treatment with a mandibular advancement splint on 24-h blood pressure in 67 patients with sleep apnea (mean $\mathrm{AHI}=27$ ). There was approximately $3.5 \mathrm{mmHg}$ drop in the systolic and diastolic blood pressure with treatment, but only during wakefulness. There was no change in blood pressure during sleep. The second study by Barnes et al. [92] compared the effect of 3 months treatment with oral appliance to CPAP and placebo (a tablet). In 110 patients with sleep apnea (mean $\mathrm{AHI}=21$ ), the $24 \mathrm{~h}$ blood pressure was measured. Treatment with oral appliance (but not with
CPAP or placebo tablet) resulted in the significant reduction in nighttime diastolic blood pressure by $2.2 \mathrm{mmHg}$. There were no changes in diastolic blood pressure during wakefulness and no changes in systolic blood pressure either during wakefulness or sleep. The third study was carried out by Yoshida [126] who measured blood pressure in 161 patients with sleep apnea before and after 60 days of treatment with oral appliance. There was a statistically significant drop in blood pressure from 132.0/82.1 to 127.5/ $79.2 \mathrm{mmHg}$. Regression analysis demonstrated weak, but significant correlation between the mean arterial and baseline blood pressures and the reduction in AHI. This area of investigation is still in its infancy, and undoubtedly, more results will be forthcoming in the future.

There are no rigorous studies of the effect of oral appliances on other vascular diseases. Eskafi et al. [99] carried out a single night, unattended, home sleep study in 17 patients with sleep apnea (mean $\mathrm{AHI}=25$ ) and congestive heart failure with periodic breathing before and after 
intervention with a mandibular advancement device. The authors found improvement in sleep apnea (mean AHI reduced from 25 to 15 ), but no improvement in periodic breathing or left ventricular ejection fraction after 6 months of treatment.

There is not enough evidence at the present time to draw any conclusions regarding the effect of oral appliance therapy on vascular disease. This remains a very interesting area of investigation. Given the differences in intra-thoracic pressure as a consequence of CPAP vs oral appliance, it is possible that results obtained with oral appliances therapy will be different from those obtained with positive pressure therapy.

\section{Side effects}

Almost every study describing oral appliances comments on the side effects voiced by patients. The type of side effects and their frequency depend on the questions asked, the rating scale, the number of patients in the study, etc. Some studies specifically focused on the side effects and compliance with treatment [101, 102, 106, 110], others simply asked a few questions about the side effects. Table 12 summarizes some of the common side effects; there is also a reference to the study, which reported the highest frequency of this particular side effect.

Excessive salivation, mouth, and teeth discomfort are the most common side effects reported. However, patients seldom consider these side effects troublesome. Provided that this complaint is addressed by the dentist and the appliance is adjusted, they continue to use it. In many cases the side effects are transient and disappear with continued use. When patients stop wearing the oral appliances it is mainly because of ineffectiveness, rather than because of side effects, although in some studies $[95,101]$ up to 40

Table 12 Patient reported side effects of oral appliances

\begin{tabular}{lll}
\hline Side effect & $\begin{array}{l}\text { Percent of } \\
\text { patients }\end{array}$ & $\begin{array}{l}\text { Reference reporting } \\
\text { maximum percent }\end{array}$ \\
\hline Difficulty in chewing & $11-19$ & {$[101]$} \\
Excessive salivation & $9-60$ & {$[106]$} \\
Dry mouth & $14-86$ & {$[73]$} \\
Tooth discomfort & $11-59$ & {$[73]$} \\
Tongue discomfort & $6-8$ & {$[101]$} \\
Jaw discomfort & $8-41$ & {$[73]$} \\
Gum discomfort & $1-2$ & {$[101]$} \\
Headache & $2-27$ & {$[89]$} \\
Occlusive changes & 41 & {$[76]$} \\
TMJ pain & 37 & {$[102]$} \\
Masseter muscle pain & 45 & {$[66]$} \\
No side effects at all & 100 & {$[39] ; 14$ subjects } \\
\hline
\end{tabular}

$50 \%$ of patients discontinued the use of the appliances because of the side effects. One study [39], involving only 14 patients all using the Herbst appliance, reported that none of the patients had any side effects! The conclusion, based on the results of most studies, is that when oral appliances are properly constructed by the dentist with expertise in this area, they are relatively comfortable in the majority of patients.

There are also dental effects of oral appliances. It is still not entirely clear if long-term use of oral appliances will lead to permanent adverse dental changes, particularly when used in children. There are several studies addressing various dental-skeletal changes of oral appliances using various imaging techniques. One of the most common effects, commented upon in many studies, is the degree of vertical and horizontal overlap of the teeth (overjet and overbite, respectively). These results are summarized in Table 13. There are 11 distinct studies, involving 694 patients with mean follow-up time of 43 months. Two studies [78, 118] were rejected because only the median results were given, and one study [127] was rejected because no mean values for overjet and overbite were shown, only changes in these parameters over a period of 3 years. A summary of the remaining data involving 389 patients with mean follow-up of 39 months shows that the overbite is reduced from 3.8 to $2.4 \mathrm{~mm}$ and the overjet is reduced from 4.0 to $2.7 \mathrm{~mm}$. It is clear that dental-skeletal effects of oral appliances are certainly present, but the longterm results and their clinical significance are unknown at this time. The recent studies of Marklund [118] and de Almeida et al. [119] described patients who were using mandibular advancement appliances for more than 5 years. Their results suggest that orthodontic changes (1) are variable (favorable in some and unfavorable in others), (2) are clinically relevant, and (3) might be predictable from the initial dental characteristics of the patients and the type of device.

\section{Compliance}

Compliance with oral appliances depends strictly on the balance between the perception of benefit and side effects. Most patients treated with oral appliances have relatively mild sleep apnea and relatively few daytime symptoms; the main reason for treatment was snoring. Consequently, the perception of benefit is generally that of the bed partner, whereas the side effects are experienced by the wearer of the appliance. This is why the assessment of compliance is a complex issue. In some cases, although the appliance is quite comfortable, the patient may stop wearing it if the bed partner is no longer present or no longer complains of snoring. 
Table 13 Dental effects: overjet and overbite

\begin{tabular}{|c|c|c|c|c|c|c|c|}
\hline \multirow[t]{2}{*}{ Reference } & \multirow[t]{2}{*}{$N$} & \multirow{2}{*}{$\begin{array}{l}\mathrm{F} / \mathrm{U} \\
\text { (months) }\end{array}$} & \multicolumn{2}{|c|}{ Overjet } & \multicolumn{2}{|c|}{ Overbite } & \multirow[t]{2}{*}{ Comments } \\
\hline & & & Base & $\mathrm{F} / \mathrm{U}$ & Base & $\mathrm{F} / \mathrm{U}$ & \\
\hline [39] & 19 & 13 & 4.0 & -3.0 & 2.9 & 6.3 & Herbst appliance \\
\hline$[108]$ & 32 & 24 & 4.5 & 4.1 & 3.6 & 3.5 & \\
\hline [71] & 22 & 6 & 5.97 & 1.08 & 3.97 & -8.01 & After correction for magnification error \\
\hline [109] & 87 & 30 & 4.25 & 3.19 & 4.09 & 3.07 & Effects evident already at 6 months \\
\hline$[73]$ & 22 & 14 & 3.3 & 3.1 & 4.0 & 3.6 & Median results at follow-up \\
\hline$[110]$ & 47 & 28 & 3.9 & 3.6 & 3.2 & 2.8 & Significantly larger changes compared to reference group \\
\hline$[110]$ & 28 & 31 & 4.5 & 3.9 & 3.8 & 3.3 & Ibid \\
\hline [81] & 34 & 30 & 4.4 & 3.1 & 3.6 & 2.5 & \\
\hline$[111]$ & 30 & 48 & 3.5 & 3.1 & 4.3 & 3.8 & NS; compared to UPPP \\
\hline$[112]$ & 20 & 30 & 3.84 & 2.63 & 4.43 & 2.61 & Effects evident at 6 months \\
\hline$[90]$ & 29 & 12 & - & - & 2.5 & 2.4 & NS; for $50 \%$ protrusion; same for $75 \%$ protrusion \\
\hline$[118]$ & 187 & 60 & 3.5 & 3.0 & 3.0 & 2.80 & $\begin{array}{l}\text { Median values; overbite change NS; orthodontic side effect increase with } \\
\text { treatment time and more frequent use }\end{array}$ \\
\hline [119] & 31 & 89 & 2.12 & 0.45 & 2.7 & 0.46 & $\begin{array}{l}70 \text { patients followed-up for } 7.4 \text { years; measurements made from models; } \\
\text { "unfavorable change" group }\end{array}$ \\
\hline [119] & 10 & 89 & 2.75 & 2.9 & 4.45 & 3.87 & As above; "no change" group \\
\hline [119] & 29 & 89 & 3.95 & 2.72 & 4.47 & 2.52 & As above; "favorable change" group \\
\hline$[127]$ & 67 & 36 & - & - & - & - & $\begin{array}{l}\text { Only changes, but not baseline values in overjet and overbite are given }(-0.8 \\
\text { and }-0.6 \text {, respectively over } 3 \text { years); small but significant reductions } \\
\text { observed mainly during the first year }\end{array}$ \\
\hline \multicolumn{8}{|l|}{ Summary } \\
\hline & 389 & 39 & 4.0 & 2.6 & & & References $[73,118]$ were excluded \\
\hline & 418 & 37 & & & 3.7 & 2.4 & \\
\hline
\end{tabular}

Table 14 shows the results of studies, which provide compliance data. All of them except one [49] employed mandibular advancement devices. There is a very wide variability between individual investigations - from as little as $4 \%$ to as high as $76 \%$ at the end of 1 year.

The largest study is that of de Almeida et al. [101]. It is based on a mail survey of 544 patients, of whom 251 returned the questionnaire on the average of almost 6 years after the construction of the appliance. The majority of patients were fitted with MAAs, although some had TRDs. At the time of follow-up, 161 patients continued to use the appliance. Assuming "the worse case scenario" (i.e. all those who did not return the questionnaire were no longer using the appliance) the compliance rate is $161 / 544=30 \%$, while in the "best case scenario" the compliance rate is 161/ $251=64 \%$. Among those who used the appliance, $82 \%$ of bed partners were satisfied with this treatment; even among the non-users of appliances, $46 \%$ of bed partners were satisfied. The main reasons for discontinuing the use of the appliance were discomfort (44\%) and perception of little or no benefit $(34 \%)$.

Pooled data summarizing all 21 reviewed studies involving 3,107 patients, showed that at the end of 33 months, $56-68 \%$ of them continued to wear the appliance.
Table 14 Compliance with oral appliances

\begin{tabular}{|c|c|c|c|}
\hline Reference & $N$ & F/U (months) & Compliance $(\%)$ \\
\hline [34] & 71 & 7 & $71-75$ \\
\hline [35] & 24 & 12 & $4-5$ \\
\hline [38] & 24 & 36 & $50-75$ \\
\hline [39] & 19 & 24 & $68-93$ \\
\hline [47] & 29 & 41 & $55-70$ \\
\hline [49] & 23 & 6 & 21 \\
\hline [103] & 191 & 31 & $52-76$ \\
\hline [107] & 45 & 12 & 82 \\
\hline [66] & 173 & 9 & $45-70$ \\
\hline [70] & 256 & 31 & 90 \\
\hline [71] & 22 & 6 & 100 \\
\hline$[76]$ & 33 & 62 & 58 \\
\hline [102] & 166 & 22 & $42-56$ \\
\hline [79] & 45 & 48 & 62 \\
\hline [81] & 86 & $18-24$ & $30-53$ \\
\hline [89] & 74 & 12 & $72-76$ \\
\hline [106] & 110 & 22 & $40-57$ \\
\hline [95] & 630 & 12 & $75-76$ \\
\hline [101] & 544 & 68 & $30-64$ \\
\hline [115] & 92 & 3 & 68 \\
\hline [118] & 450 & 60 & 56 \\
\hline \multicolumn{4}{|l|}{ Summary } \\
\hline & 3,107 & 33 & $56-68$ \\
\hline
\end{tabular}




\section{Conclusions}

Oral appliances used to date constitute a relatively heterogeneous group of devices for the treatment of sleep apnea and non-apneic snoring. It is this heterogeneity, which partly accounts for the variability in their benefit and side effects. Another reason for variability is the diverse methodology employed in different studies. The evidence available at present indicates that oral appliances successfully "cure" mild-to-moderate sleep apnea in $40-50 \%$ of patients, and significantly improve it in additional $10-20 \%$. They reduce, but do not eliminate snoring. Side effects are common, but are relatively minor. Provided that the appliances are constructed by qualified dentists, $50-70 \%$ of patients continue to use them for several years. Their effectiveness is inferior to CPAP. It is similar to surgical procedures, but these are invasive, (although not particularly dangerous) and irreversible. The effect of oral appliances on the vascular consequences of sleep apnea is not known.

The place of oral appliances in the spectrum of treatment options for apneic and non-apneic snorers was extensively discussed in various reviews and guidelines, including the most recent report by the American Academy of Sleep Medicine [124, 125]. The current review does not alter those conclusions. It simply illustrates the marked variability of individual responses to oral appliance therapy, and therefore the necessity to approach each patient on an individual basis. Patients with sleep apnea should be informed about all treatment options. In some cases, the decision is simple; after informing patients about all available options, a strong and clear recommendation can be given by the health care practitioner. In other cases, the decision regarding treatment is arrived at only after individual consideration of all the factors-urgency of clinical situation, reimbursement plan available to patient, risk factors and the patient's ability or motivation to modify them, patient's preferences, and a possibility of having a trial of treatment with oral appliance and CPAP. There are patients with severe sleep apnea successfully treated with oral appliances, just as there are non-apneic snorers with or without upper airway resistance syndrome, successfully treated with CPAP. The decision regarding treatment in each individual patient is best made by medical practitioners with experience in sleep medicine who are aware of all options, and who are preferably a part of a specialized sleep disorders center.

An important issue, not addressed in this review, is the underuse of oral appliances currently. This is due in part to the lack of qualified dentists working in this area and in part to reimbursement policies. At present, the majority of government-sponsored and private health care providers will cover (fully or partially) the cost of CPAP, whereas very few, if any, health care plans will cover the cost of oral appliances. Considering that this treatment approach is the only non-invasive alternative to CPAP, it is important to continue to lobby health care providers to enable this treatment for qualified patients.

\section{References}

1. Hoekema A, Stegenga B, De Bont LG (2004) Efficacy and comorbidity of oral appliances in the treatment of obstructive sleep apnea-hypopnea: a systematic review. Crit Rev Oral Biol Med $15: 137-155$

2. Ferguson KA (2003) The role of oral appliance therapy in the treatment of obstructive sleep apnea. Clin Chest Med 24:355-364

3. Mohsenin N, Mostofi MT, Mohsenin V (2003) The role of oral appliances in treating obstructive sleep apnea. J Am Dent Assoc $34: 442-449$

4. Ivanhoe JR, Attanasio R (2001) Sleep disorders and oral devices. Dent Clin North Am 45:733-758

5. Lindman R, Bondemark L (2001) A review of oral devices in the treatment of habitual snoring and obstructive sleep apnoea. Swed Dent J 25:39-51

6. Schoem SR (2000) Oral appliances for the treatment of snoring and obstructive sleep apnea. Otolaryngol Head Neck Surg 122: 259-262

7. Bian H (2004) Knowledge, opinions, and clinical experience of general practice dentists toward obstructive sleep apnea and oral appliances. Sleep Breath 8:85-90

8. Catlin G (1872) The breath of life. Wiley, New York

9. Robin P (1902) Demonstration pratique sur la construction et la mise enbouche d'un Nouvelle appareil de redressement. Revue de Stomatologie (Paris) 9:561-590

10. Robin P (1934) Glossoptosis due to atresia and hypotrophy of the mandible. Am J Dis Child 48:541-547

11. Cartwright RD, Samelson CF (1982) The effects of a nonsurgical treatment for obstructive sleep apnea. The tongue-retaining device. JAMA 248:705-709

12. Schwab RJ (2003) Sleep apnea is an anatomic disorder. Am J Respir Crit Care Med 168:270-271

13. Strohl KP (2003) Con: sleep apnea is not an anatomic disorder. Am J Respir Crit Care Med 168:271-272

14. Ryan CF, Love LL, Fleetham JA, Lowe AA (1999) Mandibular advancement oral appliance therapy for obstructive sleep apnea: effect on awake calibre of the velopharynx. Thorax 54:972-977

15. Gale DJ, Sawyer RH, Woodcock A, Stone P, Thompson R, O'Brien K (2000) Do oral appliances enlarge the airway in patients with obstructive sleep apnea? A prospective computerized tomographic study. Eur J Orthod 22:159-168

16. Kato J, Isono S, Tanaka A, Watanabe T, Araki D, Tanzawa H, Nishino $T$ (2000) Dose-dependent effects of mandibular advancement on pharyngeal mechanics and nocturnal oxygenation in patients with sleep-disordered breathing. Chest 117: 1065-1072

17. Hiyama S, Tsuiki S, Ono T, Kuroda T, Ohyama K (2003) Effects of mandibular advancement on supine airway size in normal subjects during sleep. Sleep 26:440-445

18. Ng AT, Gotsopoulos H, Qian J, Cistulli PA (2003) Effect of oral appliance therapy on upper airway collapsibility in obstructive sleep apnea. Am J Respir Crit Care Med 168: 238-241

19. Battagel JM, Johal A, Kotecha BT (2005) Sleep nasendoscopy as a predictor of treatment success in snorers using mandibular advancement splints. J Laryngol Otol 119:106-112 
20. Petit FX, Pépin JL, Bettega G, Sadek H, Raphaël B, Lévy P (2002) Mandibular advancement devices: rate of contraindications in 100 consecutive obstructive sleep apnea patients. Am J Respir Crit Care Med 166:274-278

21. Cartwright R, Venkatesan TK, Caldarelli D, Diaz F (2000) Treatments of snoring: a comparison of somnoplasty and an oral appliance. Laryngoscope 110:1680-1683

22. Cartwright RD (1985) Predicting response to the tongue retaining device for sleep apnea syndrome. Arch Otolaryngol 111(6): 385-388

23. Caldarelli DD, Cartwright RD, Lilie JK (1985) Obstructive sleep apnea: variations in surgical management. Laryngoscope 95 (9 Pt 1):1070-1073

24. Soll BA, George PT (1985) Treatment of obstructive sleep apnea with a nocturnal airway-patency appliance. $\mathrm{N}$ Engl $\mathrm{J}$ Med 313:386-387

25. Kloss W, Meier-Ewert K, Schäfer H (1986) Zur therapie des obstruktiven schlaf-apnoe-syndroms. Fortschr Neurol Psychiatr 54:267-271

26. Meier-Ewert K, Brosig B (1987) Treatment of sleep apnea by prosthetic mandibular advancement. In: Peter H, Podszus T, von Wichert P (eds) Sleep related disorders and internal medicine. Springer, Berlin Heidelberg New York, pp 341-345

27. George PT (1987) A modified functional appliance for treatment of obstructive sleep apnea. J Clin Orthod 21:171-175

28. Bonham PE, Currier GF, Orr WC, Othman J, Nanda RS (1988) The effect of a modified functional appliance on obstructive sleep apnea. Am J Orthod Dentofacial Orthop 94:384-392

29. Bernstein AK, Reidy RM (1988) The effects of mandibular repositioning on obstructive sleep apnea. Cranio 6:179-181

30. Cartwright R, Stefoski D, Caldarelli D, Kravitz H, Knight S, Lloyd S, Samelson C (1988) Toward a treatment logic for sleep apnea: the place of the tongue retaining device. Behav Res Ther 26(2):121-126

31. Lowe AA, Fleetham JA, Ryan F, Mathews B (1990) Effects of a mandibular repositioning appliance used in the treatment of obstructive sleep apnea on tongue muscle activity. Prog Clin Biol Res 345:395-404

32. Cartwright R, Ristanovic R, Diaz F, Caldarelli D, Adler G (1991) A comparative study of treatments for positional sleep apnea. Sleep 14:546-552

33. Ichioka M, Tojo N, Yoshizawa M, Chida M, Miyazato I, Taniai S, Marumo F, Nakagawa K, Hasegawa M (1991) A dental device for the treatment of obstructive sleep apnea: a preliminary study. Otolaryngol Head Neck Surg 104:555-558

34. Schmidt-Nowara WW, Meade TE, Hays MB (1991) Treatment of snoring and obstructive sleep apnea with dental orthosis. Chest 99:1378-1385

35. Nakazawa Y, Sakamoto T, Yasutake R, Yamaga K, Kotorii T, Miyahara Y, Ariyoshi Y, Kameyama T (1992) Treatment of sleep apnea with prosthetic mandibular advancement. Sleep 15: 499-504

36. Knudson RC, Meyer JB (1993) Managing obstructive sleep apnea. J Am Dent Assoc 124:75-78

37. George PT (1993) Treatment of snoring and obstructive sleep apnea with a dental device. Gen Dent 41:294-298

38. Clark GT, Arand D, Chung E, Tong D (1993) Effect of anterior mandibular positioning on obstructive sleep apnea. Am Rev Respir Dis 147:624-629

39. Eveloff SE, Rosenberg CL, Carlisle CC, Millman RP (1994) Efficacy of a Herbst mandibular advancement device in obstructive sleep apnea. Am J Respir Crit Care Med 149: 905-909

40. Yoshida K (1994) Prosthetic therapy for sleep apnea syndrome. J Prosthet Dent 72:296-302
41. Sjöholm TT, Polo OJ, Rauhala ER, Vuoriluoto J, Helenius HY (1994) Mandibular advancement with dental appliances in obstructive sleep apnea. J Oral Rehabil 21:595-603

42. O'Sullivan RA, Hillman DR, Mateljan R, Pantin C, Finucane KE (1995) Mandibular advancement splint: an appliance to treat snoring and obstructive sleep apnea. Am J Respir Crit Care Med 151:194-198

43. Osseiran HS (1995) Treating obstructive sleep apnea: can an intraoral prosthesis help? J Am Dent Assoc 126:461-466

44. Mayer G, Meier-Ewert K (1995) Cephalometric predictors for orthopaedic mandibular advancement in obstructive sleep apnea. Eur J Orthod 17:35-43

45. Clark GT, Blumenfeld I, Yoffe N, Peled E, Lavie P (1996) A crossover study comparing the efficacy of continuous positive airway pressure with anterior mandibular positioning devices on patients with obstructive sleep apnea. Chest 109:1477-1483

46. Ferguson KA, Ono T, Lowe A, Keenan SP, Fleetham JA (1996) A randomized crossover trial of an oral appliance vs nasalcontinuous positive airway pressure in the treatment of mildmoderate obstructive sleep apnea. Chest 109:1269-1275

47. Menn SJ, Loube DI, Morgan TD, Mitler MM, Berger JS, Erman MK (1996) The mandibular repositioning device: role in the treatment of obstructive sleep apnea. Sleep 19:794-800

48. Miles PG, Nimkarn Y, De Leeuw BJ (1996) Dentistry's role in obstructive sleep apnea. Review and case report. Aust Dent J $41: 248-251$

49. Schönhofer B, Stoohs RA, Rager H, Wenzel M, Wenzel G, Köhler D (1997) A new tongue advancement technique for sleep-disrodered breathing: side effects and efficacy. Am J Respir Crit Care Med 155:732-738

50. Ferguson KA, Ono T, Lowe AA, al-Majed S, Love LL, Fleetham JA (1997) A short-term controlled trial of an adjustable oral appliance for the treatment of mild to moderate obstructive sleep apnea. Thorax 52:362-368

51. Esaki K, Kanegae H, Uchida T, Mizuma H, Sakamoto T, Kameyama T (1997) Treatment of sleep apnea with a new separated type of dental appliance (mandibular advancing positioner). Kurume Med J 44:315-319

52. Arai H, Furuta H, Koshino Y, Sano J (1997) Long-term effects of a dental appliance therapy: a case of obstructive sleep apnea syndrome with enuresis. Sleep 20:158-159

53. Lamont J, Baldwin DR, Hay KD, Veale AG (1998) Effect of two types of mandibular advancement splints on snoring and obstructive sleep apnoea. Eur J Orthod 20:293-297

54. Marklund M, Franklin KA, Sahlin C, Lundgren R (1998) The effect of mandibular advancement device on apneas and sleep in patients with obstructive sleep apnea. Chest 113:707-713

55. Millman RP, Rosenberg CL, Carlisle CC, Kramer NR, Kahn DM, Bonitati AE (1998) The efficacy of oral appliances in the treatment of persistent sleep apnea after uvulopalatopharyngoplasty. Chest 113:992-996

56. Cohen R (1998) Obstructive sleep apnea: oral appliance therapy and severity of condition. Oral Surg Oral Med Oral Pathol Oral Radiol Endod 85:388-392

57. Stradling JR, Negus TW, Smith D, Langford B (1998) Mandibular advancement devices for the control of snoring. Eur Respir J 11:447-450

58. Pellanda A, Despland PA, Pasche P (1999) The anterior mandibular positioning device for the treatment of obstructive sleep apnoea syndrome: experience with the Serenox. Clin Otolaryngol Allied Sci 24:134-141

59. Wilhelmsson B, Tegelberg A, Walker-Engstrom ML, Ringqvist M, Andersson L, Krekmanov L, Ringqvist I (1999) A prospective randomized study of a dental appliance compared with 
uvulopalatopharyngoplasty in the treatment of obstructive sleep apnea. Acta Otolaryngol 119:503-509

60. Pancer J, Al-Faifi S, Al-Faifi M, Hoffstein V (1999) Evaluation of variable mandibular advancement appliance for treatment of snoring and sleep apnea. Chest 116:1511-1518

61. Gao X, Zeng X, Fu M (1999) Magnetic resonance imaging in dental appliance treatment of obstructive sleep apnea syndrome. Zhonghua Kou Qiang Yi Xue Za Zhi 34:347-350

62. Ryan CF, Love LL, Peat D, Fleetham JA, Lowe AA (1999) Mandibular advancement oral appliance therapy for obstructive sleep apnea: effect on awake caliber of the velopharynx. Thorax 54:972-977

63. Henke KG, Frantz DE, Kuna ST (2000) An oral elastic mandibular advancement device for obstructive sleep apnea. Am J Respir Crit Care Med 161:420-425

64. Kato J, Isono S, Tanaka A, Watanabe T, Araki D, Tanzawa H, Nishino T (2000) Dose-dependent effects of mandibular advancement on pharyngeal mechanics and nocturnal oxygenation in patients with sleep-disordered breathing. Chest 117:1065-1072

65. Barthlen GM, Brown LK, Wiland MR, Sadeh JS, Patwari J, Zimmerman M (2000) Comparison of three oral appliances for treatment of severe obstructive sleep apnea syndrome. Sleep Med 1:299-305

66. Shadaba A, Battagel JM, Owa A, Croft CB, Kotecha BT (2000) Evaluation of the Herbst mandibular advancement splint in the management of patients with sleep-related breathing disorders. Clin Otolaryngol Allied Sci 25:404-412

67. Lowe AA, Sjoholm TT, Ryan CF, Fleetham JA, Ferguson KA, Remmers JE (2000) Treatment, airway and compliance of a titratable oral appliance. Sleep 23(Suppl 4):S172-S178

68. Bloch KE, Iseli A, Zhang JN, Xie X, Kaplan V, Stoeckli PW, Russi EW (2000) A randomized, controlled corssover trial of two oral appliances of sleep apnea treatment. Am J Respir Crit Care Med 162:246-251

69. Maurer JT, Hirth K, Mattinger C, Riedel F, Werner B, Hormann $\mathrm{K}$ (2000) Use of an intraoral snoring therapy device of thermolabile plastic. HNO 48:302-308

70. Yoshida (2000) Effects of a mandibular advancement device for the treatment of sleep apnea syndrome and snoring on respiratory function and sleep quality. Cranio 18:98-105

71. Liu Y, Park YC, Lowe AA, Fleetham JA (2000) Supine cephalometric analysis of adjustable oral appliance used in the treatment of obstructive sleep apnea. Sleep Breath 4:59-66

72. Mehta A, Qian J, Petocz P, Darendeliler MA, Cistulli PA (2001) A randomized, controlled study of a mandibular advancement splint for obstructive sleep apnea. Am J Respir Crit Care Med 163:1457-1461

73. Fritsch KM, Iseli A, Russi EW, Bloch KE (2001) Side effects of mandibular advancement devices for sleep apnea treatment. Am J Respir Crit Care Med 164:813-818

74. Yoshida K (2001) Influence of sleep posture on response to oral appliance therapy for sleep apnea syndrome. Sleep 24:538-544

75. Johnston CD, Gleadhill IC, Cinnamond MJ, Peden WM (2001) Oral appliances for the management of severe snoring: a randomized controlled trial. Eur J Orthod 23:127-134

76. Marklund M, Sahlin C, Stenlund H, Persson M, Franklin KA (2001) Mandibular advancement device in patients with obstructive apnea: long-term effects on apnea and sleep. Chest 120:162169

77. Pitsis AJ, Darendeliler MA, Gotsopoulos H, Petocz P, Cistulli PA (2002) Effect of vertical dimension on efficacy of oral appliance therapy in obstructive sleep apnea. Am J Respir Crit Care Med 166:860-864

78. Pételle B, Vincent G, Gagnadoux F, Rakotonanahary D, Meyer B, Fleury B (2002) One-night mandibular advancement titration for obstructive sleep apnea syndrome. Am J Respir Crit Care Med 165:1150-1153

79. Walker-Engström ML, Tegelberg Å, Wilhelmsson B, Ringqvist I (2002) 4-year follow-up of treatment with dental appliance or uvulopalatopharyngoplasty in patients with obstructive sleep apnea: a randomized study. Chest 121:739-746

80. Rose EC, Barthlen GM, Staats R, Jonas IE (2002) Therapeutic efficacy of an oral appliance in the treatment of obstructive sleep apnea: a 2-yr follow-up. Am J Orthod Dentofacial Orthop 121:273-279

81. Rose EC, Staats R, Virchow C Jr, Jonas IE (2002) Occlusal and skeletal effects of an oral appliance in the treatment of sleep apnea. Chest 122:871-877

82. Gotsopoulos H, Chen C, Qian J, Cistulli PA (2002) Oral appliance therapy improves symptoms in obstructive sleep apnea: a randomized, controlled trial. Am J Respir Crit Care Med 166:743-748

83. de Almeida FR, Bittencourt LR, de Almeida CI, Tsuiki S, Lowe AA, Tufik S (2002) Effects of mandibular posture on obstructive sleep apnea severity and the temporomandibular joint in patients fitted with an oral appliance. Sleep 25:507-513

84. Randerath WJ, Heise M, Hinz R, Ruehle KH (2002) An individually adjustable oral appliance vs. continuous positive airway pressure in mild-to-moderate obstructive sleep apnea syndrome. Chest 122:569-575

85. Engleman HM, McDonald JP, Graham D, Lello GE, Kingshott RN, Coleman EL, Mackay TW, Douglas NJ (2002) Randomized crossover trial of two treatments for sleep apnea/hypopnea syndrome: continuous positive pressure and mandibular reposition splint. Am J Respir Crit Care Med 166:855-859

86. Johnston CD, Gleadhill IC, Cinnamond MJ, Gabbey J, Burden DJ (2002) Mandibular advancement appliances and obstructive sleep apnea: a randomized clinical trial. Eur J Orthod 24:251-262

87. Smith DM, Stradling JR (2002) Can mandibular advancement devices be a satisfactory substitute for short term use in patients on nasal continuous positive airway pressure? Thorax 57: 305-308

88. Tan YK, L'Estrange PR, Luo YM, Smith C, Grant HR, Simonds AK, Spiro SG, Battagel JM (2002) Mandibular advancement splints and continuous positive airway pressure in patients with obstructive sleep apnoea: a randomized cross-over trial. Eur J Orthod 24:239-249

89. Walker-Engström ML, Ringqvist I, Vestling O, Wilhelmsson B, Tegelberg $\AA$ (2003) A prospective randomized study comparing two different degrees of mandibular advancement with a dental appliance in treatment of severe sleep apnea. Sleep Breath 3:119-130

90. Tegelberg Å, Walker-Engström ML, Ringqvist I, Vestling O, Wilhelmsson B (2003) Two different degrees of mandibular advancement with a dental appliance in treatment of patients with mild to moderate obstructive sleep apnea. Acta Odontol Scand 61:356-362

91. Wade PS (2003) Oral appliance therapy for snoring and sleep apnea: preliminary report on 86 patients fitted with an anterior mandibular positioning device, the Silencer. J Otolaryngol 32:110-113

92. Barnes M, McEvoy RD, Banks S, Tarquinio N, Murray CG, Vowles N, Pierce RJ (2004) Efficacy of positive airway pressure and oral appliance in mild to moderate obstructive sleep apnea. Am J Respir Crit Care Med 170:656-664

93. Fleury B, Rakotonanahary D, Petelle B, Vincent G, Pelletier Fleury N, Meyer B, Lebeau B (2004) Mandibular advancement titration for obstructive sleep apnea: optimization of the procedure by combining clinical and oximetric parameters. Chest 125:1761-1767 
94. Tsai WH, Vazquez JC, Oshima T, Dort L, Roycroft B, Lowe AA, Hajduk E, Remmers JE (2004) Remotely controlled mandibular positioner predicts efficacy of oral appliances in sleep apnea. Am J Respir Crit Care Med 170:366-370

95. Marklund M, Stenlund H, Franklin KA (2004) Mandibular advancement devices in 630 men and women with obstructive sleep apnea and snoring: tolerability and predictors of treatment success. Chest 125:1270-1278

96. Smith AM, Battagel JM (2004) Non-apneic snoring and the orthodontist: the effectiveness of mandibular advancement splints. J Orthod 31:115-123

97. Vanderveken OM, Boudewyns AN, Braem MJ, Okkerse W, Verbraecken JA, Willemen M, Wuyts FL, De Backer WA, Van de Heyning PH (2004) Pilot study of a novel mandibular advancement device for the control of snoring. Acta Otolaryngol 124:628-633

98. Rose EC, Germann M, Sorichter S, Jonas IE (2004) Case control study in the treatment of obstructive sleep-disordered breathing with a mandibular protrusive appliance. J Orofac Orthop 65: 489-500

99. Eskafi M, Cline C, Israelsson B, Nilner M (2004) A mandibular advancement device reduces sleep disordered breathing in patients with congestive heart failure. Swed Dent J 28:155-163

100. Lawton HM, Battagel JM, Kotecha B (2005) A comparison of the Twin Block and Herbst mandibular advancement splints in the treatment of patients with obstructive sleep apnoea: a prospective study. Eur J Orthod 27:82-90

101. de Almeida FR, Lowe AA, Tsuiki S, Otsuka R, Wong M, Fastlicht S, Ryan CF (2005) Long term compliance and side effects of oral appliances used for the treatment of snoring and obstructive sleep apnea syndrome. J Clin Sleep Med 1:143-152

102. McGown AD, Makker HK, Battagel JM, L'Estrange PR, Grant HR, Spiro SG (2001) Long-term use of mandibular advancement splints for snoring and obstructive sleep apnea: a quesionnaire survey. Eur Respir J 17:462-466

103. Pantin CG, Hillman DR, Tennant M (1999) Dental side effects of an oral device to treat snoring and obstructive sleep apnea. Sleep 22:237-240

104. Clark GT, Sohn JW, Hong CN (2000) Treating obstructive sleep apnea and snoring: assessment of an anterior mandibular positioning device. J Am Dent Assoc 131:765-771

105. Minhas SS, Dutt SN, Deakin P, Pahor AL (2001) Mandibular advancement prosthesis: first-line alternative to surgery in snoring. J Laryngol Otol 115:548-551

106. Dort LC, Hussein J (2004) Snoring and obstructive sleep apnea: compliance with oral appliance therapy. J Otolaryngol 33:172-176

107. Walker-Engström ML, Wilhelmsson B, Tegelberg A, Dimenäs E, Ringqvist I (2000) Quality of life assessment of treatment with dental appliance or UPPP in patients with mild to moderate obstructive sleep apnoea. A prospective randomized 1-year follow-up study. J Sleep Res 9:303-308

108. Bondemark L, Lindman R (2000) Craniomandibular status and function in patients with habitual snoring and obstructive sleep apnea after nocturnal treatment with a mandibular advancement splint: a 2-year follow-up. Eur J Orthod 22:53-60

109. Robertson CJ (2001) Dental and skeletal changes associated with long-term mandibular advancement. Sleep 24:531-537

110. Marklund M, Franklin KA, Persson M (2001) Orthodontic sideeffects of mandibular advancement devices during treatment of snoring and sleep apnea. Eur J Orthod 23:135-144

111. Ringqvist M, Walker-Engström ML, Tegelberg A, Ringqvist I (2003) Dental and skeletal changes after 4 years of obstructive sleep apnea treatment with mandibular advancement device: a prospective, randomized study. Am J Orthod Dentofacial Orthop 124:53-60

112. Robertson C, Herbison P, Harkness M (2003) Dental and occlusal changes during mandibular advancement splint therapy in sleep disordered patients. Eur J Orthod 25:371-376

113. Gotsopoulos H, Kelly JJ, Cistulli PA (2004) Oral appliance therapy reduces blood pressure in obstructive sleep apnea: a randomized, controlled trial. Sleep 27:934-941

114. Kuna ST, Giarraputo PC, Stanton DC, Levin LM, Frantz D (2006) Evaluation of an oral mandibular advancement titration appliance. Oral Surg Oral Med Oral Pathol Oral Radiol Endod 101:593-603

115. Bates CJ, McDonald JP (2006) Patients' and sleeping partners' experience of treatment for sleep-related breathing disorders with a mandibular repositioning splint. Br Dent J 200:95-101

116. Liu Y, Lowe AA, Fleetham JA, Park YC (2001) Cephalometric and physiologic predictors of the efficacy of an adjustable oral appliance for treating obstructive sleep apnea. Am J Orthod Dentofacial Orthop 120:639-647

117. Otsuka R, Almeida FR, Lowe AA, Ryan F (2006) A comparison of responders and nonresponders to oral appliance therapy for the treatment of obstructive sleep apnea. Am J Orthod Dentofacial Orthop 129:222-229

118. Marklund M (2006) Predictors of long-term orthodontic side effects from mandibular advancement devices in patients with snoring and obstructive sleep apnea. Am J Orthod Dentofacial Orthop 129:214-221

119. de Almeida FR, Lowe AA, Otsuka R, Fastlicht S, Farbood M, Tsuiki S (2006) Long-term sequellae of oral appliance therapy in obstructive sleep apnea patients: part 2. Study-model analysis. Am J Orthod Dentofacial Orthop 129:205-213

120. Horiuchi A, Suzuki M, Ookubo M, Ikeda K, Mitani H, Sugawara J (2005) Measurement techniques predicting the effectiveness of an oral appliance for obstructive sleep apnea hypopnea syndrome. Angle Orthod 75:1003-1011

121. Hoekema A, de Lange J, Stegenga B, de Bont LG (2006) Oral appliances and maxillomandibular advancement surgery: an alternative treatment protocol for the obstructive sleep apnea-hypopnea syndrome. J Oral Maxillofac Surg 64:886-891

122. Naismith SL, Winter VR, Hickie IB, Cistulli PA (2005) Effect of oral appliance therapy on neurobehavioral functioning in obstructive sleep apnea: a randomized controlled trial. J Clin Sleep Med 1:374-380

123. Ng AT, Qian J, Cistulli PA (2006) Oropharyngeal collapse predicts treatment response with oral appliance therapy in obstructive sleep apnea. Sleep 29:666-671

124. Kushida CA, Morgenthaler TI, Littner MR, Alessi CA, Bailey D, Coleman J Jr, Friedman L, Hirshkowitz M, Kapen S, Kramer M, Lee-Chiong T, Owens J, Pancer JP (2006) Practice parameters for the treatment of snoring and obstructive sleep apnea with oral appliances: an update for 2005. Sleep 29:240-243

125. Ferguson KA, Cartwright R, Rogers R, Schmidt-Nowara W (2006) Oral appliances for snoring and sleep apnea: a review. Sleep 29:244-262

126. Yoshida K (2006) Effect on blood pressure of oral appliance therapy for sleep apnea syndrome. Int J Prosthodont 19:61-66

127. Hou HM, Sam K, Hägg U, Rabie ABM, Bendeus M, Yam LYC, Ip MS (2006) Long-term dentofacial changes in Chinese obstructive sleep apnea patients after treatment with mandibular advancement device. Angle Orthod 73:432-440 